\title{
The Political Economy of Flexicurity
}

\author{
Tito Boeri* \\ Università Bocconi, IGIER, and Fondazione Rodolfo Debenedetti \\ J. Ignacio Conde-Ruiz \\ Universidad Complutense de Madrid, and FEDEA \\ Vincenzo Galasso \\ IGIER, Università Bocconi and CEPR
}

December 2009

\begin{abstract}
We document the presence of a trade-off in the labor market between the protection of jobs and the support offered to unemployed people. Different countries' locations along this trade-off represent stable politico-economic equilibria. We develop a model in which individuals determine the mix of job protection and support to the unemployed in a political environment. Agents are heterogeneous along two dimensions: employment status - insiders and outsiders - and skills - low and high. Unlike previous work on the political economy of labor market institutions, we emphazes the role of job protection and unemployment benefits in the wage setting process. A key implication of the model is that flexicurity configurations with low job protection and high support to the unemployed should emerge in presence of a highly educated workforce. Panel regressions of countries' locations along this institutional tradeoff are consistent with the implications of our model.

Keywords: job protection, unemployment insurance, active labor market policies, political equilibria. JEL Classification: J68, J65, D72.

${ }^{*}$ Tito Boeri, Università Bocconi, IGIER and Fondazione Rodolfo Debenedetti, via Roentgen 1, Milano, 20136, tito.boeri@unibocconi.it. Jose Ignacio Conde-Ruiz, Fundación de Estudios de Economía Aplicada (FEDEA), C/ Jorge Juan, 46, 28001 Madrid (Spain), Tlf. +34 914359020, conderuiz@fedea.es, Vincenzo Galasso, IGIER, Università Bocconi, via Roentgen 1, 20136, Milano, vincenzo.galasso@unibocconi.it. We thank Alberto Alesina, Pierre Cahuc, Lars Calmfors, Pietro Garibaldi, Guido Tabellini and two anonymous referees for useful comments and Domenico Tabasso for skilful research assistance. All remaining errors are ours.
\end{abstract}




\section{Introduction}

According to the President of the European Union, Josè Manuel Barroso, "flexicurity is essential if Europe is to preserve both its competitive edge and social model in a globalised world" ${ }^{1}$. Even in the rethorics of the official documents of the EU, flexicurity is defined as "flexible contracts" and "adequate unemployment benefits" coupled with "a strong emphasis on active labor market policies", that is, less rigid employment protection legislation (EPL) and greater expenditure on unemployment benefits (UB) and active labor market policies (ALMP) per unemployed (EC, 2007). The institutional tradeoff alluded in the EU documents is in the data: European countries with more expenditure on UB and ALMP per unemployed have less EPL, and vice versa. But moving along this institutional tradeoff is proving very difficult. Countries' locations along this tradeoff correspond to stable political-economic equilibria. Reforms of EPL have mostly been confined to introducing more flexible contractual types for new hires, without modifying rules for workers who already have a permanent contract. UB systems have experienced modifications of the enforcement rules, increasing the scope of activation schemes, but modest, if any, changes in statutory replacement rates or in the maximum duration of benefits. This means that some countries continue to protect more the jobs than the unemployed people and others do just the opposite concentrating their attention on providing support to the unemployed people rather than protecting the jobs.

Why do European countries resort to so much different combinations of these institutions? Are these institutions actually operating some form of redistribution in the labor market across individuals with different employment status and education? Why is it so difficult to modify these institutional configurations?

To address these issues, this paper applies for the first time (to our knowledge) a multidimensional voting approach to endogenous labor market institutions theory. A

\footnotetext{
${ }^{1}$ See http://ec.europa.eu/commission_barroso/president/focus/flexicurity.
} 
growing literature in the political economy of labor markets has singularly analyzed these issues in one-dimensional models (see Wright, 1986, Saint-Paul, 1996, 1999a, 1999b and 2000, Pallage and Zimmermann, 2001, Hassler and Rodriguez Mora, 1999, Hassler et al., 2005). Our theoretical framework puts together and expands on the environments proposed by Wright (1986) to examine UB, and by Saint-Paul (1996, 1999a, 1999b and 2000) in modeling choices over EPL. We acknowledge that both EPL and UB share the objective of providing insurance against otherwise uninsurable labor market risk. At the same time, however, EPL protects the employees against the risk of job loss, without imposing a tax burden on the worker, while UB transfer income to the unemployed and are funded by a tax on labor income. We consider the role of these two policies in the bargaining process over the workers' wages, and address also their redistributive aspects.

Unlike Wright and Saint-Paul, we model EPL and UB as multidimensional institutions operating redistributions from insiders to outsiders, but also affecting the wage formation of high and low-skill types. Hence, we introduce two conflicts of interest in our model. The first conflict is between insiders and outsiders arises in the transition between employment and unemployment: unemployment inflow and outflow rates are affected by the strictness of EPL. The second conflict is in the traditional class struggle between rich and poor (high skill and low skill types) and occurs because both EPL and UB operate - at different degrees - some redistribution across skills, both directly and indirectly, that is, via their design features as well as wage setting and skill complementarities in the production function.

The strictness of EPL and the size of UB are determined in the political system. Because of the multidimensionality of the issue space, the existence of a Condorcet winner of the majority voting game is not guaranteed. We hence consider a political system in which the entire electorate votes simultaneously over the payroll tax financing unemployment benefits (hence over the size of UB), and over the strictness of EPL; and 
policy decisions are taken issue-by-issue. In other words, we concentrate on steady state structure-induced equilibria (as defined by Shepsle, 1979, see also Persson and Tabellini, 2000). This equilibrium concept allows us to retain the flavour of the median voter approach even in a multidimensional setting and thus to highlight more clearly the crucial relevance of the differential impact of UB and EPL according to the individuals' types. In this framework, the median voter over the UB is a low-skill or high-skill insider, while the pivotal voter over the degree of EPL may be a low ability insider or outsider, or a high-skill type, depending on the distribution of the population by skill level.

We show that flexicurity configurations, with relatively low EPL and high UB, emerge in societies with a large (but not necessarily majoritarian) share of educated individuals. These qualitative results are robust to a wide range of modifications in the specification of the economic and political environment.

Our empirical strategy offers tests of these implications of the model. We run panel regressions both over OECD countries (where we have better data on labor market institutions) and over the 54 countries in the world with both EPL and UB, obtaining results which are in line with the model's predictions. In particular we find a positive effect of education on the probability of adopting a flexicurity configuration. The progressiveness embedded in the UB system or in the structure of income taxes also favors flexicurity configurations in the countries with more developed capital markets.

The paper proceeds as follows: Section 2 documents the tradeoff, characterizes the multidimensional conflicts involved by UB and EPL and reviews the related literature. Section 3 presents the model and the economic environment. Section 4 develops the political system, introduces the equilibrium concept, and discusses extensions of the model. In section 5, we bring the model's main assumptions and results to the data, and we conclude. 


\section{The trade-off between unemployment policies and job protection}

The theoretical literature acknowledging a welfare-enhancing role to labor market institutions suggests that UB may be a close substitute for EPL. Clearly, both EPL and UB protect workers against uninsurable labor market risk. When severance payments and notice periods in case of dismissals are chosen optimally to maximize welfare of risk-adverse agents, there is no role for unemployment insurance (Pissarides, 2001). These two institutions have also important design features in common. An experiencerated unemployment insurance scheme involves the same type (and possibly amount) of transfers from the employer to the employee than a severance pay or a statutory notice period in the event of a dismissal. The only difference is that EPL would be paid in one installment, while UB are generally provided throughout the unemployment spell up to their maximum duration. The reform of the French unemployment benefit system advocated by Blanchard and Tirole (2003) exploits this substitutability between EPL and UB: it involves an increase in the degree of experience-rating of the UB system, which confines EPL to a one-off monetary compensation for the job loss.

However, a very few countries currently allow for experience-rating in their UB systems. The standard unemployment benefit system is funded via compulsory contributions paid by all workers and employers, independently of the number of redundancies in the firm. This makes it more difficult to substitute EPL with UB as payroll taxes are paid by all firms, even those that are upsizing. Flexicurity involves, in addition to the substitution of EPL with UB, the adoption of activation policies aimed at improving the cost effectiveness of UB by monitoring job search efforts of unemployment benefit recipients. In particular the offer of slots in some active labor market programme (subsidized jobs, training schemes or public works) is used as a device to enforce work tests, eliciting whether the UB recipient is actually willing to work and actively seeking employment. This clearly also requires the buildup of some administrative capacity, an adequately staffed Public Employment Service (PES), sanctioning with benefit cuts 
those unemployed who refuse a suitable job offer. These benefit sanctions are used as a deterrent, to discourage opportunistic behavior by the UB recipients.

Figure 1 documents the aggregate trade-off between unemployment policies and job protection over the European countries for which we had comparable data on EPL, UB and on expenditure on ALMP and PES. In particular, it displays, on the horizontal axis, an index of the strictness of employment protection compiled by the OECD (OECD, 1999) on the basis of an assessment of national legislations. The vertical axis displays the expenditure in UB, ALMP and PES per unemployed person, a summary measure of the stance of unemployment policies.Data are obtained from the OECD Social Expenditure database.

Both job protection and unemployment policies measures are normalized and rescaled in the 0-1 range. Higher values denote stricter job protection and more spending per unemployed respectively. Data are averages for the 1996-2005 period. The figure hints at an inverse relationship between the provision of job protection and the generosity of unemployment policies. The UK is an outlier as it displays markedly less of both institutions according to available measures.

Table 1 displays correlation coefficients between the measures displayed in Fig 1, as well as other measures of unemployment policies. In particular, we consider also the coverage of unemployment benefits (UBcov, the fraction of unemployed people receiving an unemployment benefit according to the EU-SILC, a comparable survey of income and living conditions), the replacement rate offered two years after the beginning of an unemployment spell (UBrr) and the product of the above two measures. As UB coverage among first-time jobseekers is partly endogenous to the strictness of EPL, which has been found to postpone first entry in the labor market of jobseekers not eligible to unemployment benefits, we also provide coverage measures for the male prime-age (25 to 45 ) group. The correlations are always negative and in most cases statistically significant when we exclude the UK. 
This trade-off holds also at the micro level. Boeri, Börsch-Supan and Tabellini (2001) found that individuals, who feel protected by EPL, are less willing to purchase state-provided unemployment insurance; Ichino et al. (2003) found that courts deciding on labor disputes are more favorable to workers (effectively making EPL stricter) when unemployment benefits are lower.

The location of the different countries along this tradeoff is fairly stable. The correlation between the 1985 and 2005 ratio of unemployment policies to job protection indicators (the two variables displayed in Figure 1) is 0.75 , which is significant at 99 confidence level; the Spearman rank correlation coefficient is also 0.75 .

Changing the country locations, e.g., moving towards flexicurity configurations towards the North West of Figure 1 is proving very difficult. Reforms of EPL, in particular, fail to change the job protection offered to insiders. An inventory of reforms (available at www.frdb.org) indicates that 93 out of 112 reforms reducing EPL carried out in the period 1986-2002 in Europe have involved the introduction of new contractual types only "at the margin". Only two European countries (Finland and Spain) out of 27 reduced EPL for the insiders (regular workers) throughout the 1987-2005 period, according to the OECD index.

\section{A Political-Economic Model}

\subsection{The environment}

In our economy, agents are infinitely long lived. In every period, they consume their current income, since, as in Wright (1986), we assume that no saving technology is available $^{2}$. Preferences are defined over the infinite stream of consumption, $c$, through a utility function, $\sum_{k=t}^{\infty} \delta^{k-t} v\left(c_{k}\right)$, with $\delta$ representing the subjective discount factor. The instant utility function is assumed to be linear $v(c)=\ln (c)$. Agents may be of low

\footnotetext{
${ }^{2}$ This assumption greatly simplifies the analysis, without affecting our qualitative conclusions. For instance, the fact that agents are not allowed to self-insure against negative labor market shocks through private savings does not affect the wage setting channel that drives in part our results.
} 
or high skill type, as indicated by the superscripts $l$ and $h$ respectively. The fraction of low and high ability workers in the population is indicated by $\rho$ and $1-\rho$ respectively. We consider that there are more low than high skill types, hence $\rho>1 / 2$.

In every period, agents may be either employed (insiders) or unemployed (outsiders). The transition between the two states is regulated by a Markov process, with skillspecific transition probabilities. In particular, $F^{j} \in(0,1)$ is the probability that a type- $j$ employed worker becomes unemployed (the unemployment inflow rate); and $H^{j} \in(0,1)$ is the probability that a type- $j$ unemployed worker finds a job (the unemployment outflow rate). Our analysis concentrates on steady states. Thus, for each group of agents the unemployment rate is $u^{j}=F^{j} /\left(H^{j}+F^{j}\right)$, while the total unemployment rate is $u=u^{l} \rho+u^{h}(1-\rho)$. Clearly, we have that $\partial u^{j} / \partial F^{j} \geq 0$ and $\partial u^{j} / \partial H^{j} \leq 0$. Moreover, we assume the unemployment rate to remain below $50 \%$, which requires $F^{j}<H^{j} \forall j$. When employed, low skill workers earn a pre-tax real wage equal to $w^{l}$, whereas high skill workers earn $w^{h}$. Employed individuals face a binary labor supply decision. They either work full time, $l^{j}=1$, if the net wage exceeds their outside option, or they do not work at all, $l^{j}=0$. Below we will discuss the conditions such that individuals always have an incentive to work, when a job is available, rather than to stay unemployed. Headcount labor supply will thus be fixed (and conveniently normalized to one) in this setup and all separations will be involuntary.

\subsection{Labor Market Institutions}

We consider two types of labor market institutions: i) job protection legislation, which affects unemployment inflow (and outflow) rates; and ii) an income support scheme for unemployed people, which in every period taxes the labor income of the workers and provides a transfer to the unemployed. Both institutions also affect wage setting.

Job Protection $(s)$ Labor markets may be regulated by norms protecting workers against the risk of job loss. Economic theory and empirical evidence suggest that it 
is mainly red-tape and procedural costs which affect labor market flows ${ }^{3}$. These costs are fixed (hence protect more low-skill workers) and deadweight from the standpoint of the employment relationship (hence cannot be replaced by experience-rated UB). Accordingly, we model EPL as protecting only the low-skill workers, and disregard the existence of pure transfers such as mandatory severance payments.

In our model, the strictness of EPL is measured by a parameter $s \in[0,1]$, where $s=0$ means no protection and $s=1$ denotes maximum protection. As in Saint-Paul (1996 and 2000), we concentrate on the effects of EPL on unemployment inflow and outflow rates, a relationship on which there is little ambiguity in the empirical ${ }^{4}$ and theoretical literature.

Consider the low skill types. A higher degree of EPL decreases the unemployment inflow rate, $\partial F^{l} / \partial s=F_{s}^{l} \leq 0$. Consistently with empirical evidence, we assume that this effect is larger when the labor market is flexible $(s \simeq 0)$ than under strict $\mathrm{EPL}^{5}$, i.e., $\partial^{2} F^{l} / \partial s^{2}=F_{s s}^{l}>0$.

Also the unemployment outflow rate is negatively affected by the strictness of EPL, $\partial H^{l} / \partial s=H_{s}^{l}<0$, in accordance with empirical evidence (OECD, 1999) and with economic theory (e.g., Bentolila and Bertola, 1990) predicting that in rigid labor markets employers hire less workers in upturns in order to reduce the costs of dismissals during downturns. Figure 2 summarizes the behavior of the low skill inflow and outflow rates as a function of the strictness of EPL. Notice that a tradeoff arises since more EPL decreases the unemployment inflow of low skill types, while reducing their outflow. The overall effect on the unemployment rate is therefore ambiguous, as in standard equilibrium

\footnotetext{
${ }^{3}$ When EPL is confined to severance pay regimes, it can be replicated by any experience-rated unemployment benefit. This makes the UB-EPL substitutability rather uninteresting in that case.

${ }^{4}$ See OECD (1999, 2004 and 2006).

5Mortensen and Pissarides' (2001) equilibrium search model also yields a convexity of the reservation productivity (hence unemployment inflows) in EPL, provided that the matching function is specialised as a Cobb-Douglas. This model also implies a negative effect of EPL on unemployment inflows and outflows. In the case of outflows, however, it is not possible to establish a priori the sign of the second derivative.
} 
search models of the labor market (Mortensen and Pissarides, 2001). Provided that unemployment inflows are negative and convex in EPL, while unemployment outflows are linearly declining in EPL, we expect unemployment to be decreasing for low levels of job protection (as the effect on unemployment inflows dominates) and increasing for larger values of $s$ (as the effect on unemployment outflows becomes relatively more important). This assumption, which is standard in the literature (see Persson and Tabellini, 2000), is consistent with empirical evidence (see OECD 1999 and Section 4 below) and delivers an interior minimum at $\widehat{s}^{l}$.

Finally, we assume for simplicity that EPL leaves the high-skill types unaffected, i.e., that $F^{h}$ and $H^{h}$ are constant ${ }^{6}$. Moreover, consistently with a large body of empirical evidence, we assume that the unemployment inflow rate is always higher for the low than for the high skill workers, i.e. $F^{l}(s) \geq F^{h} \forall s$, and that, for any degree of EPL, the unemployment outflow rate of the high skill workers is higher than the outflow rate of the low skill ones $\left(H^{l}(s) \leq H^{h} \forall s\right)$. It follows that, for any level of EPL, the unemployment rate is higher among the low skill types, a fact largely documented by the literature.

Unemployment Benefits $(\tau)$ Our UB program awards a transfer, $b^{j}$, to a type-j unemployed agent. Transfers are financed by a contribution rate, $\tau$, on the workers' labor income. We consider a separate system for the low-skilled and for the high-skilled individuals, since we choose to abstract from the redistributive element often associated with the UB schemes ${ }^{7}$. The UB systems are assumed to be budget balanced in every

\footnotetext{
${ }^{6}$ This is another easily alterable assumption. In a companion paper (see Boeri, Conde-Ruiz and Galasso, 2003), we show that our results hold also in an environment in which EPL affects unemployment inflow and outflow rates of the high-skill types, provided that unemployment flows are less responsive for the high-skill types than for the low-skill individuals and that low-income insiders constitute a majority of the voters.

${ }^{7}$ Redistribution may occurs for two reasons. First, if benefits are constant across types, while the program is financed through a proportional tax on labor income, high skill types contribute more than the others. Second, high skill workers are less likely to become unemployed. Introducing redistribution in this environment would only strengthen our results. See section 4.4.1 for a discussion.
} 
period. Thus, the UB transfers provided to a type-j unemployed individual is:

$$
b^{j}=\frac{\tau l^{j} w^{j}\left(1-u^{j}\right)}{u^{j}}
$$

where $\left(1-u^{j}\right)$ is headcount employment among the type- $j$ individuals.

Hence, the unemployment benefits depend on the unemployment rate, on the wage bill, and on the level of taxation. For a given level of taxation, $\tau$, high skilled agents will hence receive a higher UB transfer and even a higher replacement rate, as measured by the ratio between the UB transfer and the previous wage, than the low skill workers.

\subsection{Wage Setting}

Employment protection and unemployment benefits also affect labor market stocks and flows indirectly, that is, via wage-setting. In particular, we assume that (pre-tax) individual wages depend on both institutions, as follows:

$$
\begin{gathered}
w^{l}=\left(1-\beta^{l}\right) b^{l}+\beta^{l} \frac{1-\delta}{\delta} \psi(s) \\
w^{h}=\left(1-\beta^{h}\right) b^{h}+\beta^{h} \frac{1-\delta}{\delta} \lambda(s)
\end{gathered}
$$

respectively for the low and high skilled workers, where $\beta^{l} \in(0,1)$ and $\beta^{h} \in(0,1)$ measure the bargaining power of low and high skilled workers, $\delta$ is the discount factor, and $\psi(s)$ and $\lambda(s)$ are functions of the strictness of job protection. In other words, wages impose a "markup" on the reservation wage (the first term on the right-handside of equations 3.2 and 3.3) which is increasing in the bargaining power of workers and depends on the degree of job protection.

This wage equation can be rationalised in terms of a reduced form Nash bargaining outcome in an equilibrium gross job flow model, like Mortensen and Pissarides (2001). When type- $j$ workers have no bargaining power, i.e., $\beta^{j}=0, w^{j}$ equals the reservation wage of workers, that is, the unemployment benefit, $b^{j}$. Higher bargaining 
power of workers allows them to obtain higher wages, to an extent that depends on the structness of job protection. When employers have no bargaining power (i.e., $\beta^{j}=1$ ), unemployment benefits do not play any role in wage setting, which is affected only by EPL, according to $\psi(s)$ for the low skilled and to $\lambda(s)$ for the high skilled. Another interpretation of equations 3.2 and 3.3 is in terms of an efficiency wage outcome, in which case $\beta^{j}$ would parametrize informational asymmetries in the monitoring of workers' productivity. The stronger these asymmetries, the more important EPL in affecting wage setting.

The rationale behind the two functions $\psi(s)$ and $\lambda(s)$ is as follows. In the case of low skilled individuals, EPL directly affect the probability of job loss and their discounted life-time unemployment rate $\theta_{I}^{l}$. As shown below, this is initially decreasing ${ }^{8}$ with $s$ and then increasing in job protection as the effects of this institution of hirings dominate. It follows that the function $\psi(s)=\psi\left(\theta_{I}^{l}(s)\right)$ is bell-shaped in $s$. For the high skilled workers, instead, the function $\lambda(s)$ captures the mark-up that workers obtain over their marginal productivity. To see why $\lambda(s)$ may depend on the degree of EPL, $s$, consider a production function that combines low and high skilled labor: $Y=\left(L^{l}\right)^{\alpha}\left(L^{h}\right)^{1-\alpha}$, where $L^{l}=\left(1-u^{l}\right) l^{l}, L^{h}=\left(1-u^{h}\right) l^{h}$, and $\alpha$ measures the relative importance of low-skill labor. Hence, this function is equal to

$$
\lambda(s)=A(1-\alpha)\left(\frac{1-u^{l}}{1-u^{h}}\right)^{\alpha}
$$

where $A$ is a mark-up and the remaining terms represent the marginal productivity of the high skilled workers. It is easy to see that this function depends positively on the employment rate of the low skill types, which complements the high skill labor in the production function, and is maximized when the degree of EPL is equal to $\widehat{s}^{l}$.

\footnotetext{
${ }^{8}$ In Mortensen and Pissarides model, wages are given by $w=(1-\beta) b+\beta\left(1+c \frac{v}{u}+\frac{1-\delta}{\delta} s\right)$ where $\frac{v}{u}$ is the vacancy to unemployed ratio and $c$ are hiring costs. In their model, $s$ is found to negatively affect market tightness, $\frac{v}{u}$. Hence the function $\psi($.$) in eq. 3.2$ can be interpreted as embodying the effect of EPL on wages via the induced change in market tightness. This declining section of the wage function captures in our setting also compensating differentials arising from risk aversion.
} 
Finally, given the wage setting at equations 3.2 and 3.3, and the existence of a UB system, notice that employed type- $j$ individuals will choose to supply labor, if $(1-\tau) w^{j}>b^{j}$, which holds for $\tau<u^{j}$.

To summarize, in our environment both labor market institutions, i.e., EPL and UB, affect the pre-tax wages of the low and high skilled workers.

\subsection{Individual Preferences}

As in Wright (1986) and Pissarides (2001), in our model individuals cannot save to insure against the unemployment risk. Thus, in every period, consumption is entirely determined by the employment status of the individuals: if employed, they consume $(1-\tau) w^{j} l^{j} ;$ if unemployed, they consume $b^{j}$.

We can now characterize the indirect utility function of each type of agents and labor market status with respect to EPL and UB. The expected lifetime utility of a type- $j$ agent who is currently in state $i$, is given by:

$$
V_{i}^{j}(s, \tau)=\frac{\left(1-\theta_{i}^{j}(s)\right) \ln \left((1-\tau) w^{j} l^{j}\right)+\theta_{i}^{j}(s) \ln \left(b^{j}\right)}{(1-\delta)}
$$

where $w^{l}$ and $w^{h}$ are defined at eq. 3.2 and 3.3, and

$$
\theta_{I}^{j}(s)=\frac{\delta F^{j}}{1-\delta+\delta\left(F^{j}+H^{j}\right)} \text { and } \theta_{O}^{j}(s)=\frac{1-\delta+\delta F^{j}}{\delta F^{j}} \theta_{I}^{j}(s)
$$

represent the (discounted) proportion of time that respectively a current insider (subscript $I$ ) and outsider (subscript $O$ ) type- $j$ will spend unemployed during their lifetime; clearly, $\theta_{O}^{j}(s)>\theta_{I}^{j}(s)$. Notice that for the high-skill types, the measure $\theta_{i}^{h}$ does not depend on EPL.

It is useful at this juncture to define the strictness of EPL which minimizes the (discounted) time spent unemployed respectively by a low-skill insider and outsider ${ }^{9}$ : $\widetilde{s}_{I}=\arg \min \theta_{I}(s)$ and $\widetilde{s}_{O}=\arg \min \theta_{O}(s)$. It is easy to see that $\widetilde{s}_{O}<\widehat{s}^{l}<\widetilde{s}_{I}-$

\footnotetext{
${ }^{9}$ Notice that, as for the unemployment rate, $u^{l}(s)$, the assumptions on $F^{l}(s)$ and $H^{l}(s)$ stated in the text are sufficient for $\theta_{I}(s)$ and $\theta_{O}(s)$ to have a minimum, albeit not to be convex.
} 
where $\widehat{s}^{l}$ is the degree of EPL which minimizes the unemployment rate of the low skillsince $\widetilde{s}_{O}$ and $\widetilde{s}_{I}$ take into account the current employment status of the agent. Figure 3 summarizes the behavior of $\theta_{I}^{l}(s), \theta_{O}^{l}(s)$, and $u^{l}$ with respect to $s$. Notice that the (subjective) discount factor, $\delta$, plays a crucial role in this context. As $\delta$ approaches 1 , current employment conditions lose their relevance and the indirect utilities of low skill insiders or outsiders coincide: $\theta_{I}^{j}=\theta_{O}^{j}=u^{j}$; whereas if $\delta$ is sufficiently low, individuals will only be concerned about their current status.

The degree of EPL affects the utility of the workers also indirectly, through its impact on the wage setting. As shown at eq. 3.2, EPL has a direct effect on the low skill wage that workers with a high bargaining power may obtain, via the function $\psi\left(\theta_{I}^{l}(s)\right)$, but also an indirect impact through its effect on the unemployment benefit, $b$. The effect through $\psi\left(\theta_{I}^{l}(s)\right)$ reaches its maximum at $s=\widetilde{s}_{I}$. Using equations 3.1 and 3.2 , we can define as $s_{b}$ the level of EPL that maximizes the UB for a given tax rate. Since the impact of EPL on the UB occurs through two channels, the unemployment rate of the low ability (that is minimized at $\widehat{s}^{\text {}}$ ), and the wage setting (and hence the function $\left.\theta_{I}^{l}(s)\right)$, it is easy to see that $\widehat{s}^{l} \leq s_{b} \leq \widetilde{s}_{I}$. In our setting, EPL thus has several positive effects on the workers' utility. To limit the magnitude of these effects, we require the average utility of a low ability worker behind a veil of ignorance to be decreasing in the degree of EPL for $s>s_{b}$ (see the annex 1). In other words, when the EPL is sufficiently large, $s>s_{b}$, for the average low skill worker the increase in the probability of becoming unemployed outweights the increase in the wage income and the utility is reduced. Equations 3.3 and 3.4 show that EPL affects also the wages of the high skilled, which are maximized for $s=\widehat{s}^{l}$.

\section{The Political Environment}

The strictness of EPL and the generosity of the UB system are determined in the political arena, where the individual preferences - described by the indirect utility functions 
at equations 3.5 and 3.6 - are aggregated into a policy outcome. Given the strong persistence of the trade-off, we concentrate on steady state equilibria. Agents vote once and for all over the income tax, which finances the unemployment benefits, $\tau$, and the strictness of EPL, $s$.

Since the issue space is bi-dimensional, $(\tau, s)$, Condorcet cycles typically arise. We hence impose on the voting game a set of institutional restrictions, which convert a multi-dimensional election into a simultaneous issue-by-issue voting game, in which a structure induced equilibrium exists (see Shapsle, 1979, and Conde-Ruiz and Galasso, 2003 and 2005). The concept of structure induced equilibrium - or issue-by-issue voting - applied to our political game can be summarized as follows. For every value of the strictness of EPL, $s$, each voter determines her most preferred generosity of UB, $\tau$; analogously, the most preferred level of $s$ is chosen for any given $\tau$. In other words, every agent votes two reaction functions: $\tau(s)$ and $s(\tau)$. A duple $\left(\tau^{*}, s^{*}\right)$ is an equilibrium of this voting game if $\tau^{*}$ represents the outcome of a majority voting over the issue $\tau$ - the level of unemployment benefits - when the other dimension is fixed at $s^{*}$, and likewise for $s^{*}$.

\subsection{Voting over EPL $(s)$}

The political decision over the EPL, $s(\tau)$, depends on the tradeoffs that EPL creates through its effects on the unemployment inflow and outflow rates, and on the wages: In fact, while the tax rate, $\tau$, is taken as given by the voters, they do realize that their choice of $s$ will affect the UB benefit, $b^{j}$ according to eq. 3.1. Consider a high-skill individual. EPL has no direct relevance for the high types' inflow and outflow rates $\left(F^{h}\right.$ and $\left.H^{h}\right)$. However, it does affect their utility by modifying their wages, according to equations 3.3 and 3.4. High-skill insiders and outsiders will hence choose the degree of EPL that maximizes their wages per any given tax rate, $s=\widehat{s}$.

The decision on the strictness of EPL for the low-skill individuals - both insiders and 
outsiders - is more complex, because of the direct impact of EPL on their inflow and outflow rates as well as on their wages. An increase of EPL has two effects on the indirect utility of the low-skill types (see eq. 3.5). First, it has an impact on the (discounted) proportion of time that a low ability individual (currently insider or outsider) spends unemployed during her lifetime, $\theta_{i}^{l}(s)$, with $i=I, O$. It is easy to see from figure 3 that this effect - by raising the discounted probability of being employed - increases the utility of the low-skill insider for $s<\widetilde{s}_{I}$, and of a low-skill outsider for $s<\widetilde{s}_{O}$. Second, an increase in EPL modifies the unemployment benefit and the wages of the low-skill type for both insiders and outsiders (see eq. 3.1 and 3.2), as discussed in section 3.3. It follows that the level of EPL voted by low-skill outsiders, $s_{O}^{l}(\tau) \in\left(\widetilde{s}_{O}, s_{b}\right)$, is less strict than the level supported by the low-skill insiders, $s_{I}^{l}(\tau) \in\left(s_{b}, \widetilde{s}_{I}\right)$, who seek to protect their current employment status. Regardless of their current status, high-skill individuals will prefer to set $s_{I}^{h}=s_{O}^{h}=\widehat{s}^{l}$. Hence, when voting on the strictness of EPL, two orderings of preferences may emerge ${ }^{10}$. If the low-skill outsiders are very concerned about their current employment status, and thus $s_{O}^{l}<\widehat{s}^{l}$, we have $s_{O}^{l}(\tau)<s_{I}^{h}(\tau)=s_{O}^{h}(\tau)=\widehat{s}^{l}<$ $s_{I}^{l}(\tau)$. Otherwise, the ordering becomes $s_{I}^{h}(\tau)=s_{O}^{h}(\tau)=\hat{s}^{l}<s_{O}^{l}(\tau)<s_{I}^{l}(\tau)$.

How do these preferences over the strictness of EPL depend on the UB level? The decision of the high-skill individuals is unaffected by the tax rate financing the UB system. For the low-skill insiders, instead, there exists a negative relationship between EPL and UB (see proposition A.1 in Annex 1), since a higher level of unemployment insurance reduces the cost, in terms of consumption, of being unemployed. Hence, lowskill insiders will demand less EPL. On the contrary, low-skill outsiders will typically want more EPL, since the negative effect of EPL on their utility when unemployed has decreased, but its positive impact on the wage setting (see eq. 3.2) remains. Examples of the reaction function of $s$ with respect to $\tau$ for a high ability and for a low ability insider are provided at Figure 5.

\footnotetext{
${ }^{10}$ Proposition A.1 in the appendix derives all the results presented in this section.
} 


\subsection{Voting over UB $(\tau)$}

In determining the tax rate that finances $\mathrm{UB}^{11}$, for any given level of EPL, $\tau(s)$, individuals consider the insurance properties of UB, and their positive effect on the wage setting. In fact, to the usual tradeoff between the costs represented by the stream of contributions when employed and the benefit of receiving a transfer when unemployed (see Wright, 1986), individuals add the impact of UB on their wages. In fact, a higher contribution rate, and hence more UB, increases their outside option, and thereby their wages in the bargaining process (see equations 3.2 and 3.3).

For a given skill type, insiders prefer a lower level of UB than outsiders, since $\theta_{I}^{j}<\theta_{O}^{j}$, i.e., they face a lower (discounted) probability of becoming unemployed. Analogously, high skilled outsiders will choose a lower tax rate than the unemployed low skilled workers. The comparison between low and high skilled insiders is instead less straightforward. In fact, low skill insiders benefit more from the insurance component of UB than high skill insiders, who in turn may gain more from the effect of UB in the wage setting. In the end, as shown at proposition A.2 in Annex 1, two possible ordering of preferences over $\tau$ may emerge. If the effect of UB on the wage setting of the high-skill dominates, and thus $\tau_{I}^{h}>\tau_{I}^{l}$, we have $\tau_{O}^{l}>\tau_{O}^{h}>\tau_{I}^{h}>\tau_{I}^{l}$. Otherwise, the ordering becomes $\tau_{O}^{l}>\tau_{O}^{h}>\tau_{I}^{l}>\tau_{I}^{h}$.

How do these preferences over the UB level depend on the strictness of EPL? The most preferred tax rate by a low-skill insider is decreasing in the strictness of EPL. The intuition is straightforward. For $s \in\left(s_{b}, \widetilde{s}_{I}\right)$, more EPL reduces the low-skill insiders' probability of being unemployed and hence to cash in the transfer. Moreover, for $s \in$ $\left(s_{b}, \widetilde{s}_{I}\right)$, an increase in EPL reduces also the level of UB - more than it increases the wages of the low skilled through the wage setting process. The reaction function of $\tau$ with respect to $s$ (see Figure 4) is thus negatively sloped. The decision of the high-skill insiders over the tax rate financing the UB system is instead unaffected by the degree

\footnotetext{
${ }^{11}$ Proposition A.2 in the appendix derives all the results presented in this section.
} 
of EPL.

\subsection{Political Equilibria}

In order to fully characterize the political equilibria of this issue-by-issue voting game, one needs to obtain the duple $\left(s^{*}, \tau^{*}\right)$ at the intersection of the two reaction functions of the low-skill insider. This is described in the next two propositions and characterized graphically in figures 4 and 5 where the reaction functions, $\tau_{I}^{l}(s)$ and $s_{I}^{l}(\tau)$, are portrayed. Proposition 4.1 explains locations along the UB-EPL trade-off, notably along the $\tau_{I}^{l}(s)$ function, as different political equilibria arising because of different proportions of high and low skilled individuals in the population.

Proposition 4.1. Two issue-by-issue equilibria of the voting game may emerge: (i) if $\rho\left(1-u^{l}\right)>1 / 2$, there exists an equilibrium $\left(s^{*}, \tau^{*}\right)$, such that $s^{*}\left(\tau^{*}\right)=s_{I}^{l}\left(\tau^{*}\right) \in$ $\left(s_{b}, \widetilde{s}_{I}\right)$ and $\tau^{*}\left(s^{*}\right)=\tau_{I}^{l}\left(s^{*}\right)$; (ii) if $\rho\left(1-u^{l}\right)<1 / 2$, there exists an equilibrium $\left(s^{* *}, \tau^{* *}\right)$, such that $s^{* *}\left(\tau^{* *}\right)=\max \left\{\hat{s}^{l}, s_{O}^{l}\left(\tau^{* *}\right)\right\}<s_{b}$ and $\tau^{* *}\left(s^{* *}\right)=\max \left\{\tau_{I}^{l}\left(s^{* *}\right), \tau_{I}^{h}\left(s^{* *}\right)\right\}$. Comparing equilibria, we have $s^{*}>s^{* *}$ and $\tau^{*} \leq \tau^{* *}$.

If they constitute a majority of the voters, low-skill insiders will dictate both labor market policies - EPL and UB. In this case, the above Proposition shows that they will adopt a strict labor market regulation $s^{*}>s_{b}$, and the (low) level of UB chosen by a low-skill insider. This UB scheme emerges due to its double role of providing insurance against the unemployment risk, and of increasing the relevance of the outside option in the wage setting process.

If instead there is a large share of high-skill individuals in the population, and thus the low-skill insiders are not a majority, they may still be pivotal in determining the UB system (if $\tau_{I}^{h}<\tau_{I}^{l}$ ), but the decision over the rigidity of the labor market (EPL) will be taken either by a high-skill individual or by a low-skill outsider, depending on the orderings of preferences over the EPL. In both cases, a lower degree of EPL will emerge. In fact, a high-skill median voter would only be concerned with maximizing the 
high-skill wage - and set $s=\widehat{s}^{l}$, while a low-skill outsider median voter would internalize more the negative effect of EPL on the unemployment, and be more conservative than a low-skill insider. Faced with less EPL - and hence with a higher probability of becoming unemployed, but also with lower wages (through $\psi(s)$ ), low-skill insiders will become more supportive of a larger UB system. Finally, notice that if high skilled insiders are

the pivotal voters over the UB system, this is because $\tau_{I}^{h}>\tau_{I}^{l}$, and thus the UB system would be even larger.

This Proposition thus explains the existence of a tradeoff between EPL and UB across groups of countries with different shares of low-high ability individuals in the population. Countries with a substantial proportion of high-skill individuals will not feature a low-skill insider as a median voter over the EPL decision (and perhaps over UB) and will have a more flexible labor market and more UB spending. Figure 5 displays these equilibrium outcomes.

\subsection{Extensions}

The results in the previous section identify a clear tradeoff between EPL and UB across countries. Despite the economic and political environment being quite stylized, these results are robust to several modifications. This section discusses some of these extensions.

\subsubsection{Redistribution and Perfect Capital Markets}

The tradeoff between EPL and UB may also be driven by a redistributive motive that involves transfers from the high to the low skill individuals through the UB system. To emphasize this element, we consider an environment in which individuals have a utility function, which is linear in consumption, so that no insurance motive is in place. If individuals are willing to demand UB, this request will have to come for redistributive reasons. To model this redistributive component of UB, we consider the benefits obtained by each individual depending on his skill type: 


$$
\begin{gathered}
b^{l}=\tau(1-\tau)\left[\frac{w^{l} l^{l}\left(1-u^{l}\right)}{u^{l}}+\phi \frac{l^{h} w^{h}(1-\rho)\left(1-u^{h}\right)}{u^{l} \rho}\right] \\
b^{h}=\tau(1-\tau)(1-\phi) \frac{l^{h} w^{h}\left(1-u^{h}\right)}{u^{h}}
\end{gathered}
$$

Hence, for $\phi=0$, no redistribution takes place and we are back to the model ${ }^{12}$ presented in section 3; while for $\phi>0$, some redistribution takes place from high to low skilled individuals. To simplify the analysis, we also assume that high skill workers have full bargaining power, that is, $\beta \rightarrow 1$, at eq. 3.3.

If sufficiently strong (large $\phi$ ), this redistributive motive will induce low skill individuals, regardless of their current labor market status, to support UB, while high skill individuals will oppose it. The voting behavior over EPL will also be modifed by the existence of a redistributive UB scheme (and, of course, by the use of a linear utility function). In particular, low skill individuals will partially internalize the effect of EPL on the high skill wages (see equations 3.3 and 3.4), since these wages now contribute to finance their unemployment benefits. Thus, low skill insiders will demand a lower level of EPL. These two effects are behind a new tradeoff EPL-UB, which may arise due to the redistribution across skill types by these two labor market institutions.

For semplicity, let us concentrate on the equilibrium in which a low skill insider is the median voter over both UB and EPL. In this case, an increase in the redistributiveness of UB will lead the median voter over UB to increase the tax rate, $\tau$, that finances UB, in order to exploit the redistributive transfer from the high skill individuals. A more redistributive UB will also lead the low ability insider to demand less job protection (lower $s$ ) in order to increase the wage of the high ability and thereby their transfers.

\footnotetext{
${ }^{12}$ Due to the linearity in the utility function, we introduced also an exogenous Laffer curve represented by the term $(1-\tau)$ at equations 4.1 and 4.2 , which was not present in the model at section 3 .
} 
Moreover, for higher UB, a low ability insider will also be less concerned about the risk of becoming unemployed and will reduce the EPL accordingly.

To summarize, more redistributive UB systems are thus associated with less EPL and more UB.

\subsubsection{Alternative political environments}

To deal with a multidimensional policy space, in which both the degree of EPL and the UB contribution rate have to be determined, we relied on a steady state version of the structure induced equilibrium, which expands the logic of the median voter into a multidimensional setting. To confirm the robustness of our results, we consider two alternative political regimes.

In a party unanimity Nash equilibrium (PUNE) (see Roemer, 1999), voters choose between two parties or coalitions according to their policy platform. Each party appeals to its own electorate, and within party decisions over the economic policy require unanimity. Suppose that there exist two parties - right and left. The left party seeks the support of low skill insiders and outsiders, while the right party seeks the support of high skill agents and of low ability insiders. Parties are assumed to be uncertain about the distribution of voter types, and the expected utility of a party coincides with the expected utility of its constituency, which is composed of three groups of actors: i) militants, who want the party to adhere as closely as possible to its principles, i.e. to its partizan ideology; ii) opportunists, who only care about winning the elections; and iii) reformists who wish to maximize the expected utility of the party's constituency. In a party unanimity Nash equilibrium, given a proposal by the opposing party, every party requires the final decision on the policy to be taken at inner-party unanimity. This coincides with unanimity between opportunists and militants, since in this case the agreement of the reformists would automatically follow. It is easy to see that the policy outcome associated with the issue-by-issue voting game in the previous political 
environment is also a party unanimity Nash equilibrium. In fact, the policy platform chosen by both parties targets the low skill insiders - which also in the previous political game at section 4.1 coincided with the pivotal (median) voters. A deviation in the policy platform by a party towards more extreme positions, such as its partizan ideology - given the other party's platform - would be welcome by the militants, but would be opposed by the opportunists, since it would reduce the party's probability of winning the election. The existence of the UB-EPL trade-off according to the population skill composition thus carries over to this alternative political scenario.

Another commonly used political environment is the probabilistic voting model (see Coughlin, 1992, and Persson and Tabellini, 2000). In this setting, two political candidates compete in a majoritarian election by adopting a political platform, namely a combination of EPL and UB, in order to maximize their probability of winning the election. The winning candidate becomes the policy-maker and implements the proposed policy. Agents vote according to the indirect utility associated to each candidate's platform, and to their degree of political ideology. Hence, both candidates determine the (same) combination of EPL and UB in order to maximize a welfare function that weights the indirect utility function of all four groups of voters: low and high skill insiders and outsiders. The solution of this political process thus resambles the issue-by-issue case in that each political candidate will determine - contemporaneously but independently - the degree of EPL and of UB. Different political equilibria emerge, characterized by different locations on the UB-EPL trade-off, depending on the relative composition of the low and high skill individuals in society.

\section{Empirical Relevance}

\subsection{Testing the key assumptions}

Our key political economy results rest on the assumption that the relationship between job protection and unemployment is non-monotonic for low skilled types. The political 
equilibria are found in a region where unemployment is increasing in job protection, but the unemployment EPL profile is U-shaped. Figure 6 displays, on the vertical axis, the 1983-2004 unemployment rates for persons with primary or lower educational attainments and, on the horizontal axis, the overall EPL index over the same period. A second order polynomial is fitted across yearly and cross-country observations and both linear and quadratic terms are highly significant ${ }^{13}$.

Bassanini and Marianna (2009) estimate comparable hiring and separation rates for OECD countries, displaying the same pattern posited in our model: bot hirings and separations are declining in EPL, but hiring is declining at a faster rate and it is higher than separation for low levels of EPL.

All this is in line with the substantive assumptions of our model. The fact that EPL, contrary to UBs, protects only a limited segment of the workforce is also consistent with the observation of more individuals concerned about job security in high-EPL and lowUB countries than in low-EPL and high-UB ones (Clark and Postel-Vinay, 2004).

\subsection{The Tradeoff and Education}

Our model implies that flexicurity configurations with more support to the unemployed and less job protection arise in presence of a higher share of skilled people in the population.

Table 2 displays results of a panel regression of the country location along the unemployment policies vs. job protection tradeoff against measures of the educational attainments of the working age population and other covariates that, according to the literature, should support strict EPL or generous UB systems. In particular, we estimated the following equation on five years average data ${ }^{14}$ (1983-87, 1988-92, 1993-97,

\footnotetext{
${ }^{13}$ The coefficient of the linear EPL term is -.0768 ( $\mathrm{t}$ statistics -2.66 ), while for the quadratic term is .0174 (2.82).

${ }^{14}$ We are forced to take five year averages by the availability of data on educational attainments only at five year frequencies (see Annex 2).
} 
1998-2002) for the OECD countries

$$
\begin{aligned}
\ln \left(1+U \exp _{i t} / E P L_{i_{t}}\right)= & a_{j}+\beta_{1} \text { LOWEDU }_{i t}+\beta_{2} \text { UBprog }_{i} * \operatorname{topMKTCAP}_{i}+ \\
& +\beta_{3} \text { ATTITUDES } S_{i t}+\beta_{4} O P E N_{i t}+\varepsilon_{i t}
\end{aligned}
$$

where $U$ exp is the expenditure on unemployment benefits or active labor market policies per unemployed, EPL is the OECD index of strictness of employment protection (limited to regular contracts, EPLreg or overall EPLall), and LOWEDU is the share of the population with primary or lower education as drawn from the Barro-Lee database (2000). UBprog measures the progressiveness of the UB system and is given by the ratio of the replacement rate offered to an unemployed who was earning $2 / 3$ of the average production worker (APW) wage to the the replacement rate of someone who was earning 150 per cent of the APW wage while topMKTCAP is a dummy capturing the quartile with the highest stock market capitalisation over GDP. Hence, the interaction between the latter two variables captures support for UB vs. EPL in countries where workers can self-insure against income losses arising from job loss, as in the extensions of our model. The variable ATTITUDES is drawn from the World Value Survey (WVS) and captures societal attitudes towards those who are abusing of UB. In particular, this variable measures the fraction of the respondents stating that "it is justifiable to claim unemployment benefits to which you are not entitled". The inclusion of this variable aims at capturing the effects of civic attitudes vis-a-vis the abuse of unemployment benefits (Algan and Cahuc, 2009) as well as the degree of social acceptability of social transfers allowing for significant vertical redistribution. It should move the tradeoff in favour of configurations more intensive of $U B$ and less of EPL. Finally OPEN measures trade turnover over GDP as provided by the Penn tables. This is in line with political economic literature suggesting that social insurance may be larger in countries more exposed to international competition (Rodrik, 1998).

Summary statistics of these variables are reported in Annex 2. The cultural variables are available only for the countries covered by the WVS. Hence, we also display 
regressions without ATTITUDES as a covariate, allowing to obtain higher degrees of freedom.

The main message delivered by our regressions is that education is very important in affecting the position of the different countries along the unemployment policies vs. job protection tradeoff. Lower educational attainments of the population are associated with less unemployment policy and more job protection. This holds whatever EPL measure we take, overall or for regular contracts, and is in line with our theoretical results. The effects are quite sizeable as a decrease by 10 percentage points of the share of low-skill workers increases flexicurity by one-fourth of the standard deviation in the distribution of the UBexp/EPL ratio. The interaction between UB progressiveness and stock market capitalisation appear also to move the tradeoff towards flexicurity configurations, but it is mostly non significant at conventional levels. The coefficients for attitudes and open never achieve statistical significance.

Table 3 displays results of a between groups panel regression of the country location along the UB/EPL trade-off over a larger set of nations. In particular, we collected data on the institutional characteristics of the 54 countries with both EPL and UB, which are listed in Annex 2. Among them here are several middle-income countries. Measurement of institutions in these countries is difficult as many legal norms, including employment protection, are poorly enforced ${ }^{15}$. The estimated equation (5.1) uses available institutional measures for this larger set of countries. In particular, we now have only a measure of $U B$ generosity, that is, the average of the gross replacement rate in the first two years of unemployment and EPL is the overall index of strictness of employment protection provided by Botero et al. (2004) for this broader set of countries, which is highly correlated with the OECD EPL index for the countries in which both indicators are available (see Annex 2). The covariates are as much as possible the same as in the regression displayed in Table 2. In particular, $E D U$ is the share of the population with

\footnotetext{
${ }^{15}$ This problem is present also in OECD countries. Only 50 per cent of US firms pay statutory severance compensations to workers being laid-off.
} 
primary or lower education as drawn from the Barro-Lee database (2000), OPEN is trade turnover over GDP as provided by the Penn tables and ATTITUDES are societal attitudes towards those who are abusing of unemployment benefits, as elicited from the World Value Survey. The interaction between stock market capitalisation and vertical redistribution operated by the UB system can only be obtained in a subset of countries and using the top to bottom marginal tax rates provided by the International Tax Database of the American Enterprise Institute and the Worldwide Tax Summaries tabulated by Price Waterhouse Coopers. For a larger set of countries, in column 3, we only control for stock market capitalisation, not interacted with progressiveness Given the larger heterogeneity of countries, in our specification we also include in all specifications a dummy capturing HIGHINCOME countries as defined by the World Bank.

The main message delivered by our regressions is once more that education is very important in affecting the position of the different countries along the UB/EPL tradeoff. Lower educational attainments of the population are associated with less UB and more EPL. The size of these effects is comparable to that observed with reference to OECD countries only.

\subsection{Dealing with the outliers}

As discussed in Section 2, the UK is an outlier in that it involves lower levels of both EPL and UB than the other (Western) European countries. As shown by Table 4 below, the UK has lower levels of unemployment policies and job protection (whatever measure we take) than the average EU country. At the same time, it displays a much stronger progressiveness in the UB design than the other European countries: the replacement rate offered to a single who was earning before unemployment $2 / 3$ of the APW wage is twice as large as the replacement rate of someone previously earning 150 of the APW wage (seventh row of the table). Moreover the UK has deeper capital markets as indicated by a stock market capitalisation over GDP which is more than twice as large 
as in the other countries of the EU15 on average. The UK also has a lower share of the population with primary or lower educational attainments than the rest of the EU, but differences in this case are second order.

Further insights as to the factors affecting countries' locations along and across the UB/EPL tradeoff come by contrasting the experience of the two European countries that experienced a reduction in EPL for regular workers in the period covered by data with that of countries with similar initial institutional configurations that did not reform EPL for regular workers. Although our model is not dynamic, it suggests that moves towards flexicurity can be eased by allowing UB to operate more vertical redistribution, i.e., by making the structure of replacement rates more progressive .

As recalled in section 2, the only reformers of EPL for regular workers in Europe were Finland and Spain. The reforms of EPL that occurred in these two countries were split into a number of milder liberalization measures. In particular, in Finland, there were three waves of reforms: in 1991, 1996 and 2001, while in Spain mild reductions of EPL for regular workers were enacted in 1994 and 1997.

Table 5 compares the experience of Spain with that of Greece and the experience of Finland with that of Denmark. These "matches" are chosen by drawing on a taxonomy of labor market and social policy institutions in the EU (Esping-Andersen, 1990), pulling together, on the one hand, the Nordics and, on the other hand, Southern European countries. In particular, variations in the level of key different policy variables are displayed in the different countries, together with differences in these variations across each pair of countries, in the spirit of double-differences analysis.

As shown by Table 5, Spain reduced EPL while experiencing an increase in the generosity and progressiveness of UB and in expenditure per unemployed, just while the opposite (or no change) was occurring in Greece. Moving to the second match, Finland reduced EPL for regular workers while making the design of its UB system more progressive and increasing expenditure per unemployed. Denmark also moved 
towards more protection of the unemployed (increasing expenditure per unemployed, notably in terms of ALMP, more than Finland), but reduced the progressiveness of its UB system and did not change EPL for regular workers.

Overall, there is some indication that countries reducing EPL for regular workers experienced an increase in the generosity of unemployment policies and in the progressiveness of UB compared with countries with broadly comparable institutional configurations at the outset, which did not reform EPL for regular workers. At these frequencies no major changes are observed in the educational attainments of the workforce. The share of the population with primary or lower education hardly changed in the four countries being considered. Increasing the progressiveness of the UB system could be the only politically feasible option for countries wishing to move towards flexicurity.

\section{Conclusions}

OECD countries provide insurance to workers against labor market risks, by combining different degrees of job protection and support to the unemployed people. The European Commission and several national Governments are often arguing in favour of adoping "flexicurity", assigning a greater weight to UB and ALMP and less importance to EPL in protecting workers against labor market risk. However, the institutional configurations of the different countries are remarkably stable and often far apart from flexicurity.

Unlike previous literature, this paper characterizes these institutions as schemes redistributing not only between insiders and outsiders, but also across skill groups. We also allow these two institutions to affect not only aggregate labor market flows, but also wage setting. Our theoretical model suggests that "flexicurity" configurations, characterized by less job protection and more support to the unemployed, should emerge in countries with a larger fraction of the population being skilled.

Empirical findings based on panels of OECD countries and of over 50 countries with both EPL and UB, are broadly in line with this theoretical implication. We also carry 
out a case-study analysis of the outliers which broadly support the model implications.

A normative implication of this result is that the European Commission, rather than asking countries to adopt flexicurity configurations, should perhaps encourage member states to upgrade their workforce by investing more in education. Another normative implication suggested by extensions of our model and results of the case studies can be stated as a political feasibility theorem for countries wishing to move towards flexicurity at higher frequencies (before that the investment in education is repaid with a significant increase in the share of high skill workers): reforms of job protection need to trade labor market flexibility with state-provided unemployment insurance which strongly redistributes in favor of the low-skill segments of the workforce.

The dynamic adjustment to a new equilibrium is a subject for future research. 


\section{References}

[1] Acemoglu, D. and R. Shimer (2000) "Productivity Gains from Unemployment Insurance", European Economics Review, 44, 1195-1224.

[2] Acemoglu, D., P. Aghion and G. Violante (2001) "Deunionization, Technical Change and Inequality", Carnegie-Rochester Conference Series on Public Policy.

[3] Algan,Y., and P. Cahuc (2009) "Civic Attitudes and Design of Labor Market Institutions: Which Countries Can Implement the Danish Flexicurity Model?", American Economic Journal: Macroeconomics 1(1), 111-45.

[4] Atkinson, A.B, and J. Micklewright, (1991) "Unemployment Compensation and Labor Market Transitions: A Critical Review," Journal of Economic Literature, 29(4), 1679-1727.

[5] Barro, R. J. and Lee, J. (2000), "International Data on Educational Attainment: Updates and Implications" CID Working Paper No. 42.

[6] Bassanini, A. and Marianna, P. (2009), Looking Inside the Perpetual-Motion Machine: Job and Worker flows in OECD countries, IZA Discussion Papers, n.4452.

[7] Bentolila, S. and G. Bertola (1990), "Firing cost and labor demand: how bad is eurosclerosis?" Review of Economic Studies 57: 381-402.

[8] Bentolila, S. and Dolado, J. (1994): Labor Flexibility and Wages: Lessons from Spain, Economic Policy, n.18, 55-99.

[9] Bertola, G. (1990): Job Security Employment and Wages, European Economic Review, 851-866.

[10] Bertola, G., Boeri, T. and Cazes, S. (2000): Employment Protection in Industrialized Countries: the Case for New Indicators, International Labour Review, n.1. 
[11] Bertola, G. and Rogerson, R. (1997): Institutions and Labor Reallocation, European Economic Review, 41, 1147-71.

[12] Blanchard, O. and Tirole, J. (2003) Contours of Employment Protection Reform, MIT Dept of Economics Working Paper Series, n. 03-35.

[13] Boeri, T., A. Börsch-Supan and G. Tabellini (2001), "Would you like to shrink the welfare state? A survey of European citizens" Economic Policy April, 9-50.

[14] Boeri, T., Conde-Ruiz J.I. and V. Galasso (2003) "Protecting against Labor Market Risk: Firing Costs or Unemployment Insurance?", CEPR Discussion Paper N. 3990.

[15] Boeri, T. and P. Garibaldi (2007) "Two Tier Reforms of Employment Protection: a Honeymoon Effect?", Economic Journal, 117, 357-385.

[16] Botero, J., Djankov, S., Porta, R. and Lopez-De-Silanes, F. (2004) "The Regulation of Labor" The Quarterly Journal of Economics, MIT Press, vol. 119(4), pages 13391382, November.

[17] Buti, M. , L. Pench ad P. Sestito (1998), "European Unemployment: contending theories and institutional complexities" Policy Paper 98/1, The Robert Schuman Centre, European University Institute.

[18] Cazes, S., T. Boeri and . Bertola (1999), "Employment Protection and Labor Market Adjustment in OECD Countries: Evolving Institutions and Variable Enforcement" ILO Employment and Training Papers 48.

[19] Conde-Ruiz, J.I. and V. Galasso (2005), "Positive Arithmetic of the Welfare State", Journal of Public Economics, 89(5-6), 933-955.

[20] Conde-Ruiz J.I. and V. Galasso (2003) "Early Retirement" Review of Economic Dynamics 6: 12-36. 
[21] EC (2007), Communication from the Commission to the Council, the European Parliament, the European Economic and Social Committee and the Committee of the Regions. Towards Common Principles of Flexicurity: More and better jobs through flexibility and security, Brussels, 27/06/07.

[22] Esping-Andersen, G. (1990) The Three Worlds of Welfare Capitalism, Princeton University Press.

[23] Hassler, J. and J.V. Rodriguez Mora (1999) "Employment Turnover and the Public Allocation of Unemployment Insurance", Journal of Public Economics, 73(1), 5583.

[24] Hassler, J., J.V. Rodriguez Mora, K. Storesletten, and F. Zilibotti (2005) "A Positive Theory of Geographic Mobility and Social Insurance", International Economic Review, 46:1, pp 263-303.

[25] Ichino, A., M.Polo and E.Rettore (2003) "Are Judges Biased by Labor Market Conditions?", European Economic Review, 47(5), 913-944.

[26] Krueger, A. B. and B. D. Meyer, (2002). "Labor supply effects of social insurance," Handbook of Public Economics, in: A. J. Auerbach \& M. Feldstein (ed.), Handbook of Public Economics, edition 1, volume 4, chapter 33, 2327-2392.

[27] Labartino, G. (2008) "Tax Wedge and the Effect on Labor Market Outcomes: Evidence from a Novel Dataset", Bocconi University, mimeo.

[28] Lazear, E. (1990), "Job Security Provisions and Employment", Quarterly Journal of Economics 105: 699-726.

[29] Marinescu, I. (2005) Are Judges Sensitive to Economic Conditions? Evidence from UK Employment Tribunals, mimeo Ioana, LSE, Harvard, and NBER 
[30] Mortensen, D. and Pissarides, C. (2001) Unemployment Responses to 'Skill-Biased' Shocks: The Role of Labor Market Policy, Economic Journal, 109 (242-265).

[31] OECD (1999, 2004 and 2006) Employment Outlook, OECD, Paris.

[32] Pallage, S. and C. Zimmermann (2001) "Voting on Unemployment Insurance", International Economic Review, 42 (4).

[33] Persson, T. and G. Tabellini (2000) Political Economics. Explaining Economic Policy. The MIT Press, Cambridge, Massachusetts, London, England.

[34] Pissarides, C. (2001) Employment Protection, Labor Economics, 8, 131-59.

[35] Rodrik, D. (1998) Why Do More Open Economies Have Bigger Governments?. Journal of Political Economy 106:5:997-1032.

[36] Roemer, J. E. (1999) The Democratic Political Economy of Progressive Taxation. Econometrica, 67: 1-19.

[37] Saint-Paul, G. (1996), "Exploring the Political Economy of Labor Market Institutions" Economic Policy 23: 265-315.

[38] Saint-Paul, G. (1999a), " The Political Economy of Employment Protection", CEPR Discussion Paper, No. 2109

[39] Saint-Paul, G. (1999b), " Assessing the Political viability of Labor Market Reform: the case of Employment Protection", CEPR Discussion Paper, No. 2136

[40] Saint-Paul, G. (2000), "The Political Economy of Labor Market Institutions" $O x$ ford University Press.

[41] Shepsle, K.A. (1979), "Institutional Arrangements and Equilibrium in Multidimensional Voting Models", American Journal of Political Science, 23(1) 
[42] Wright, R (1996), "The Redistributive roles of Unemployment Insurance and the Dynamics of Voting", Journal of Public Economics 31: 377-399. 


\section{Annex 1: Proofs of the main propositions}

To impose some restriction on the positive role of the EPL, we consider the optimization problem of an average low ability type, who determines her most preferred degree of EPL, behind a veil of ignorance. The first order condition of this optimization problem is:

$$
\Im(s)=-\frac{\partial u^{l}}{\partial s}\left(V_{E}-V_{U}\right)+\left(1-u^{l}\right) \frac{\partial V_{E}}{\partial s}+u^{l} \frac{\partial V_{U}}{\partial s}
$$

where $V_{E}=\ln \left((1-\tau) w^{l}\right), V_{U}=\ln \left(b^{l}\right), \frac{\partial V_{E}}{\partial s}=\frac{\partial w^{l}}{\partial s} \frac{1}{w^{l}}$, and $\frac{\partial V_{U}}{\partial s}=\frac{\partial b^{l}}{\partial s} \frac{1}{b^{l}}$. Defining $\Delta=V_{E}-V_{U}$, we have that the following assumption guarantees that for an average low income individual, behind a veil of ignorance, the EPL increases her utility for $s<s_{b}$, and reduces it for $s \geq s_{b}$.

Assumption $1 \Im(s)<0$ for $s \geq s_{b}$. Thus, $-\frac{\partial u^{l}}{\partial s} \Delta+\left(1-u^{l}\right) \frac{\partial w^{l}}{\partial s} \frac{1}{w^{l}}+u^{l} \frac{\partial b^{l}}{\partial s} \frac{1}{b^{l}}<0$.

It is convenient to define the following elasticities: $\eta_{\theta_{O}, s}=\frac{\partial \theta_{O}^{l}}{\partial s} \frac{s}{\theta_{O}^{l}}$ and $\eta_{\psi, s}=\frac{\partial \psi}{\partial s} \frac{s}{\psi}$.

Proposition .1 (A.1). When voting over the degree of EPL, $s$, for a given $\tau$, we have that:

1. high ability (insiders and outsiders) set $s_{i}^{h}(\tau)=\widehat{s}^{l}$ with $i=I, O, \forall \tau ; \widehat{s}^{l}$ does not depend on $\tau$;

2. low ability insiders set $s_{I}^{l}(\tau) \in\left(s_{b}, \widetilde{s}_{I}\right), s_{I}^{l}(\tau)$ is decreasing in $\tau$;

3. low ability outsiders set $s_{O}^{l}(\tau) \in\left(\widetilde{s}_{O}, s_{b}\right), s_{O}^{l}(\tau)>\widehat{s}^{l}$ if $\theta_{O}^{l} \Delta \eta_{\theta_{O}, s}<\eta_{\psi, s}$;

4. The median voter over $s$ is a low ability insider if $\left(1-u^{l}\right) \rho>1 / 2$, a high ability individual if $\left(1-u^{l}\right) \rho<1 / 2$ and $\theta_{O}^{l} \Delta \eta_{\theta_{O}, s}>\eta_{\psi, s}$; and a low-skill outsider if $\left(1-u^{l}\right) \rho<1 / 2$ and $\theta_{O}^{l} \Delta \eta_{\theta_{O}, s}<\eta_{\psi, s}$. 


\section{Proof of Proposition A.1.}

1. For high ability individuals, choosing $s$ for a given $\tau$ amounts to maximize eq. 3.5 w.r.t. $s$ where only $w^{h}$ depends on $s$, as shown at equations 3.3 and 3.1. It is easy to see that the utility of the high skill, both insiders and outsiders, is maximized when the employment rate of the low-skill is maximized, i.e., for $s_{i}^{h}(\tau)=\widehat{s}^{l}$ for all $\tau$. Furthermore, $\widehat{s}^{l}$ does not depend on $\tau$.

2. For low ability insider, the maximization problem of choosing $s$ for a given $\tau$ is characterized by the following FOC, with $i=I$ :

$$
-\Delta \frac{\partial \theta_{i}^{l}(s)}{\partial s}+\frac{1-\theta_{i}^{l}(s)}{w^{l}}\left[(1-\beta) \frac{\partial b^{l}}{\partial s}+\beta \frac{1-\delta}{\delta} \psi^{\prime} \frac{\partial \theta_{I}^{l}(s)}{\partial s}\right]+\frac{\theta_{i}^{l}(s)}{b^{l}} \frac{\partial b^{l}}{\partial s}
$$

It is easy to see that this is positive if evaluated at $s=s_{b}$, since $\frac{\partial b^{l}}{\partial s}=0$, and all other terms are positive (notice that $\frac{\partial \theta_{I}^{l}}{\partial s}<0$ at $s=s_{b}$, and $\psi^{\prime}<0$ always). Moreover, if evaluated at $s=\widetilde{s}_{I}$, the FOC at eq. .1 is negative, since $\frac{\partial \theta_{I}^{l}(s)}{\partial s}=0$, while all other terms are negative (notice that $\frac{\partial b l}{\partial s}<0$ at $s=\widetilde{s}_{I}>s_{b}$ ). Simple algebra shows that, for a given $\tau, V_{I}^{l}(s, \tau)$ achieves a global maximun, $s_{I}^{l}(\tau)$, in the interval $\left(s_{b}, \widetilde{s}_{I}\right)$. Also, the second order condition of the above maximization evaluated at $s_{I}^{l}(\tau)$ is negative, so that $s_{I}^{l}(\tau) \in\left(s_{b}, \widetilde{s}_{I}\right)$ is a maximum. To prove that $s_{I}^{l}(\tau)$ is decreasing in $\tau$, we use the total differential on the FOC at eq. .1. Since the SOC is negative at $s_{I}^{l}(\tau)$, the sign of $d s / d \tau$ corresponds to the sign of 
$d F O C(s) / d \tau:$

$$
\begin{aligned}
\frac{d F O C(s)}{d \tau}= & \underbrace{-\frac{\partial \theta_{I}^{l}}{\partial s}\left[\frac{(1-\tau) \frac{\partial w^{l}}{\partial \tau}-w^{l}}{(1-\tau) w^{l}}\right]}_{I}+\underbrace{\frac{\partial \theta_{I}^{l}}{\partial s} \frac{1}{b^{l}} \frac{\partial b^{l}}{\partial \tau}}_{I I} \\
& +\underbrace{\left(1-\theta_{I}^{l}\right) \frac{1-\beta}{w^{l}}\left[\frac{\partial^{2} b^{l}}{\partial s \partial \tau}-\frac{1-\beta}{w^{l}} \frac{\partial b^{l}}{\partial s} \frac{\partial b^{l}}{\partial \tau}-\frac{\beta}{w^{l}} \frac{1-\delta}{\delta} \frac{\partial \psi}{\partial s} \frac{\partial b^{l}}{\partial \tau}\right]}_{I V}(.2) \\
& +\underbrace{\frac{\theta_{I}^{l}}{b^{l}}\left[\frac{\partial b^{l}}{\partial s} \frac{1}{b^{l}} \frac{\partial b^{l}}{\partial \tau}-\frac{\partial^{2} b^{l}}{\partial s \partial \tau}\right]}_{I I I}
\end{aligned}
$$

where $\frac{\partial b^{l}}{\partial \tau}>0$, and for $s \in\left(s_{b}, \widetilde{s}_{I}\right), \frac{\partial \theta_{I}^{l}}{\partial s}<0, \frac{\partial u^{l}}{\partial s}>0$, and $\frac{\partial b^{l}}{\partial s}<0$, so that terms $I$ and $I I$ are clearly negative. Moreover,

$$
\frac{\partial^{2} b^{l}}{\partial s \partial \tau}=\frac{\partial b^{l}}{\partial s} \frac{u^{l}}{\tau\left(u^{l}-\tau\left(1-u^{l}\right)(1-\beta)\right)}-\frac{\partial u^{l}}{\partial s} \frac{b^{l}(1-\beta)}{\left(u^{l}-\tau\left(1-u^{l}\right)(1-\beta)\right)^{2}}<0 .
$$

Simple algebra shows that also terms $I I I$ and $I V$ are negative, and hence, $d F O C(s) / d \tau$ $<0$.

3. For low ability outsiders, the first order condition resulting from the maximization problem of choosing $s$ for a given $\tau$ amounts to eq. .1 with $i=O$. It is easy to see that - for a low ability outsider, i.e., $i=O-$ the FOC at eq. .1 is positive if evaluated at $s=\widetilde{s}_{O}$, since the former term is equal to zero, while the others are positive (notice that $\frac{\partial b^{l}}{\partial s}>0$ and $\frac{\partial \theta_{I}^{l}}{\partial s}<0$ at $s=\widetilde{s}_{O}^{l}$ ). On the other hand, if evaluated at $s=s_{b}$, the FOC is negative. To see this, notice that the expression at eq. .1 is negative at $s=s_{b}$ if $-\frac{\partial \theta_{O}^{l}}{\partial s} \Delta+\left(1-\theta_{O}^{l}\right) \frac{1}{w^{l}} \beta \frac{1-\delta}{\delta} \psi^{\prime} \frac{\partial \theta_{I}^{l}}{\partial s}<0$. It is easy to verify that assumption 1 at $s=s_{b}$ becomes $-\frac{\partial u^{l}}{\partial s} \Delta+\left(1-u^{l}\right) \frac{1}{w^{l}} \beta \frac{1-\delta}{\delta} \psi^{\prime} \frac{\partial \theta_{I}^{l}}{\partial s}<0$, which implies the condition above. Simple algebra shows that, for a given $\tau$, $V_{O}^{l}(s, \tau)$ achieves a global maximun, $s_{O}^{l}(\tau)$, in the interval $\left(\widetilde{s}_{O}, s_{b}\right)$. Also, the second order condition of the above maximization problem evaluated at $s_{O}^{l}(\tau)$ is 
negative, so that $s_{O}^{l}(\tau) \in\left(\widetilde{s}_{O}, s_{b}\right)$ is a maximum. Finally, to have $s_{O}^{l}(\tau)<\widehat{s}^{l}$, we need to have the FOC at eq. .1 to be negative if evaluated at $s=\widehat{s}^{l}$. Notice that $\frac{\partial w}{\partial s}=(1-\beta) \frac{\partial b^{l}}{\partial s}+\beta \frac{1-\delta}{\delta} \frac{\partial \psi}{\partial s}$ (from eq. 3.2) and $\frac{\partial b^{l}}{\partial s}=\frac{\tau \beta\left(1-u^{l}\right)}{u^{l}-\tau\left(1-u^{l}\right)(1-\beta)} \frac{1-\delta}{\delta} \frac{\partial \psi}{\partial s}$ at $s=\hat{s}^{l}$. Using simple algebra, the FOC at eq. .1 can be written as $-\Delta \frac{\partial \theta_{O}^{l}(s)}{\partial s}+\frac{\partial \psi}{\partial s} \frac{1}{\psi}$, which is negative for $\theta_{O}^{l} \Delta \eta_{\theta_{O}, s}>\eta_{\psi, s}$, where $\eta_{\theta_{O}, s}=\frac{\partial \theta_{O}^{l}}{\partial s} \frac{s}{\theta_{O}^{l}}$ and $\eta_{\psi, s}=\frac{\partial \psi}{\partial s} \frac{s}{\psi}$.

4. Given the results obtained above, there are two possible rankings of the voters' preferences: (i) $\tilde{s}_{O}<s_{O}^{l}(\tau)<s_{I}^{h}(\tau)=s_{O}^{h}(\tau)=\widehat{s}^{l}<s_{I}^{l}(\tau)<\widetilde{s}_{I}$, and (ii) $\tilde{s}_{O}<s_{I}^{h}(\tau)=s_{O}^{h}(\tau)=\widehat{s}^{l}<s_{O}^{l}(\tau)<s_{I}^{l}(\tau)<\widetilde{s}_{I}$. For $\left(1-u^{l}\right) \rho>1 / 2$, the low ability insiders constitute a majority of the population and hence their most preferred level of EPL represents the Condorcet winner over $s$. If $\left(1-u^{l}\right) \rho<1 / 2$, the median voter over $s$ can be a high ability individual (case i) or a low ability outsider (case ii). Case (i) arises when $s_{O}^{l}(\tau)<\widehat{s}^{l}$, which happens for $\theta_{O}^{l} \Delta \eta_{\theta_{O}, s}>$ $\eta_{\psi, s}$, and viceversa for case (ii). Although the preferences of low skilled insiders and outsiders may not be single peaked over the entire range of $s$, it is easy to show that the low skilled insiders' preferences are single peaked for $s<\widehat{s}^{l}$, and the low skilled outsiders' preferences are single peaked for $s>\widehat{s}^{l}$. Hence, low skilled insiders prefer $\widehat{s}^{l}$ to any other $s<\widehat{s}^{l}$; while low skilled outsiders prefer $\widehat{s}^{l}$ to any other $s>\widehat{s}^{l}$, so that $\widehat{s}^{l}$, as chosen by the high skill individuals, is a Condorcet winner over $s$ in case (i). The same logic applies in case (ii). q.e.d.

Proposition .2 (A.2). When voting over the size of the UB system, $\tau$, for a given degree of EPL $s$, we have that:

1. type-j outsiders prefer $\tau_{O}^{j}(s)=u^{j}$;

2. type-j insiders prefer $\tau_{I}^{j}(s)=\left\{\begin{array}{cc}\frac{u^{j} \theta_{I}^{j}}{u^{j}-(1-\beta)\left(1-u^{j}\right)\left(1-\theta_{I}^{j}\right)} & \text { if } \beta>\underline{\beta^{j}}=1-\frac{u^{j}-\theta_{I}^{j}}{\left(1-u^{j}\right)\left(1-\theta_{I}^{j}\right)} \\ u^{j} & \text { otherwise }\end{array}\right.$, where $\tau_{I}^{l}(s)$ is decreasing in $s$ for $\beta>\underline{\beta^{l}}$, and $\tau_{I}^{h}$ does not depend on $s$. 
3. the median voter over $s$ is a low skill insider, if $\left(1-u^{l}\right) \rho>1 / 2$, or if $\left(1-u^{l}\right) \rho<$ $1 / 2$ and $\tau_{I}^{l}(s)>\tau_{I}^{h}(s)$; and a high skill insider if $\left(1-u^{l}\right) \rho<1 / 2$ and $\tau_{I}^{l}(s)<$ $\tau_{I}^{h}(s)$.

\section{Proof of Proposition A.2.}

The first order condition resulting from the maximization problem of choosing $\tau$ for a given $s$ is equal to

$$
-\frac{1-\theta_{i}^{j}}{1-\tau}+\left[\frac{\left(1-\theta_{i}^{j}\right)(1-\beta)}{w^{j}}+\frac{\theta_{i}^{j}}{b^{j}}\right] \frac{\partial b^{j}}{\partial \tau}=0 \quad i=I, O \text { and } j=l, h
$$

with $\frac{\partial b^{j}}{\partial \tau}=\frac{b^{j} u^{j}}{\tau\left[u^{j}-\tau\left(1-u^{j}\right)(1-\beta)\right]}$, which can be written as

$$
-\frac{1-\theta_{i}^{j}}{1-\tau}+\frac{\theta_{i}^{j}}{\tau}+\frac{\left(1-u^{j}\right)(1-\beta)}{u^{j}-\tau\left(1-u^{j}\right)(1-\beta)}=0 \quad i=I, O \text { and } j=l, h
$$

To see that preferences are single peaked, consider the second order condition below

$$
-\frac{1-\theta_{i}^{j}}{(1-\tau)^{2}}-\frac{\theta_{i}^{j}}{\tau^{2}}+\left[\frac{\left(1-u^{j}\right)(1-\beta)}{u^{j}-\tau\left(1-u^{j}\right)(1-\beta)}\right]^{2} i=I, O \text { and } j=l, h
$$

which, using the FOC at eq. .5, can be rewritten as

$$
-\frac{\left(1-\theta_{i}^{j}\right) \theta_{i}^{j}}{(1-\tau)^{2}}-\frac{\left(1-\theta_{i}^{j}\right) \theta_{i}^{j}}{\tau^{2}}-\frac{2\left(1-\theta_{i}^{j}\right) \theta_{i}^{j}}{\tau(1-\tau)}<0 \quad i=I, O \text { and } j=l, h
$$

1. From eq. .5 , it is easy to see that type- $j$ outsiders would want to set $\tau_{O}^{j}>\theta_{O}^{j}>$ $u^{j}$, but this would induce type-j individuals not to supply labor when employed. Hence, we have $\tau_{O}^{j}(s)=u^{j} \forall j=l, h$;

2. From eq. .5, using simple algebra, we have that $\tau_{I}^{j}(s)=\frac{u^{j} \theta_{I}^{j}}{u^{j}-(1-\beta)\left(1-u^{j}\right)\left(1-\theta_{I}^{j}\right)}$. It is easy to see that $\tau_{I}^{j}(s)<u^{j}$ if $\beta>\underline{\beta^{j}}$; Notice that, since $\theta_{I}^{h}$ and $u^{h}$ do not depend on $s$, hence $\tau_{I}^{h}$ does not depend on $s$. Instead, $\tau_{I}^{l}(s)$ will depend on $s$. In particular, we have 


$$
\frac{\partial \tau_{I}^{l}(s)}{\partial s}=-\frac{\partial u^{l}}{\partial s} \frac{(1-\beta)\left(1-\theta_{I}^{l}\right) \theta_{I}^{l}}{u^{l}-\tau\left(1-u^{l}\right)(1-\beta)}+\frac{\partial \theta_{I}^{l}}{\partial s} \frac{u^{l}\left[u^{l}-\left(1-u^{l}\right)(1-\beta)\right]}{\left[u^{l}-\tau\left(1-u^{l}\right)(1-\beta)\right]^{2}}<0
$$

since in the relevant range, $s \in\left(s_{b}, \widetilde{s}_{I}\right), \frac{\partial u^{l}}{\partial s}>0 \frac{\partial \theta_{I}^{l}}{\partial s}<0$ and $u^{l}>\tau\left(1-u^{l}\right)(1-\beta)$.

3. The above results imply that $\tau_{O}^{h}=u^{h}<\tau_{O}^{l}=u^{l}, \tau_{i}^{l}(s) \leq u^{l}$, and $\tau_{i}^{h}(s) \leq u^{h}$. Hence, three ranking are possible: (1) $\tau_{O}^{l}>\tau_{O}^{h} \geq \tau_{I}^{h} \geq \tau_{I}^{l}$; (2) $\tau_{O}^{l}>\tau_{O}^{h} \geq \tau_{I}^{l} \geq \tau_{I}^{h}$; and (3) $\tau_{O}^{l} \geq \tau_{I}^{l}>\tau_{O}^{h} \geq \tau_{I}^{h}$. Clearly, the median voter is always a low skill insider, if $\left(1-u^{l}\right) \rho>1 / 2$. The median voter is still a low skill insider, if $\left(1-u^{l}\right) \rho<1 / 2$ and $\tau_{I}^{l}(s)>\tau_{I}^{h}(s)$, so that we are in ranking (2) or (3), since $u^{j}<1 / 2 \forall j$ and $\rho>1 / 2$. If instead $\left(1-u^{l}\right) \rho<1 / 2$ and $\tau_{I}^{l}(s)<\tau_{I}^{h}$, so that we are in ranking $(1)$, the median voter is a high skill insider.

Proof of Proposition 4.1: We need to show that the reaction functions $\tau(s)$ and $s(\tau)$ cross at least once. Recall that: $\tau_{I}^{l}(s) \in\left(0, u^{l}\right)$ for $\beta>\underline{\beta^{l}}$ is decreasing in $s ; \tau_{I}^{h}$ does not depend on $s ; s_{I}^{l}(\tau) \in\left(s_{b}, \widetilde{s}_{I}\right)$ is decreasing in $\tau ; s_{I}^{h}(\tau)=\widehat{s}^{l}$ does not depend on $\tau$, and $s_{O}^{l}(\tau) \in\left(\hat{s}^{l}, s_{b}\right)$.

Consider case (i). For $s \in\left[s_{b}, \widetilde{s}_{I}\right]$, we have $\tau(s)=\tau_{I}^{l}(s) \in\left(0, u^{l}\right)$ with $\partial \tau / \partial s<$ 0 . For $\tau \in\left[0, u^{l}\right]$, we have $s(\tau)=s_{I}^{l}(\tau) \in\left(s_{b}, \widetilde{s}_{I}\right)$ with $\partial s / \partial \tau<0$. Hence, the two reaction functions cross in an interior $\left(s^{*}, \tau^{*}\right)$, i.e., $s^{*} \in\left(s_{b}, \widetilde{s}_{I}\right)$ and $\tau^{*} \in\left(0, u^{l}\right)$. In case (ii), if $\theta_{O}^{l} \Delta \eta_{\theta_{O}, s} \geq \eta_{\psi, s}$, the median voter over $s$ is a high skill, and hence $s=\widehat{s}^{l}$. Then, it is easy to see that the two reaction functions cross at $s=\widehat{s}^{l}$ and $\tau\left(\widehat{s}^{l}\right)=\max \left\{\tau_{I}^{l}\left(\widehat{s}^{l}\right), \tau_{I}^{h}\left(\widehat{s}^{l}\right)\right\} \in\left(0, u^{l}\right)$. In case (ii), but for $\theta_{O}^{l} \Delta \eta_{\theta_{O}, s}<\eta_{\psi, s}$, the median voter over $s$ is a low skill outsiders. Simple algebra shows that, for $\tau \rightarrow 0$, $s_{O}^{l}(\tau) \rightarrow \widetilde{s}_{O}$; while, for $\tau \rightarrow u^{l}, s_{O}^{l}(\tau) \rightarrow s_{b}$. However, the function $s_{O}^{l}(\tau)$ needs not to be monotonic. Hence, the reaction functions will cross at least once in a interior point $\left(s^{* *}, \tau^{* *}\right)$, with $s^{* *}=s_{O}^{l}\left(\tau^{* *}\right) \in\left(\widetilde{s}_{O}, s_{b}\right)$ and $\tau^{* *}=\max \left\{\tau_{I}^{l}\left(s^{* *}\right), \tau_{I}^{h}\left(s^{* *}\right)\right\} \in\left(0, u^{l}\right)$. 
However, additional cross points, and hence equilibria, may exist, with the total number of points being odd. q.e.d 


\section{Annex 2: Descriptive Statistics}

The regression analysis displayed in Table 3 is carried out over the following countries having both EPL and UB.

\begin{tabular}{lll}
\hline \hline Argentina & Greece & Philippines \\
Australia & Hong & Poland \\
Austria & Hungary & Portugal \\
Belgium & India & Romania \\
Bolivia & Indonesia & Russia \\
Brazil & Ireland & Senegal \\
Canada & Israel & Singapore \\
Chile & Italy & Spain \\
China & Jamaica & Sri Lanka \\
Colombia & Japan & Sweden \\
Denmark & Kenya & Thailand \\
Dominican Republic & Korea & Uganda \\
Egypt & Malaysia & United Kingdom \\
Finland & Mexico & United States \\
France & Netherlands & Venezuela \\
Germany & Norway & Zimbabwe \\
Ghana & Pakistan & \\
Greece & Peru & \\
\hline \hline
\end{tabular}

The table below provides summary statistics for the variables used in the regression over 24 OECD countries (period 1985-2000), whose results are displayed in Table 2. The Barro-Lee (2000) educational attainment variable is available only at 5-year frequencies. For the remaining variables we have yearly observations. 


\begin{tabular}{|c|c|c|c|c|}
\hline Variable & Mean & Std. Dev. & Min & $\operatorname{Max}$ \\
\hline Uexp & 0.18 & 0.15 & 0.02 & 0.74 \\
\hline EPL all (OECD index) & 1.99 & 1.04 & 0.21 & 3.85 \\
\hline EPL reg (OECD index) & 2.02 & 0.91 & 0.17 & 4.33 \\
\hline $\ln (1+\mathrm{Uexp} /$ EPLall $)$ & 2.30 & 0.72 & 0.91 & 3.82 \\
\hline $\ln (1+$ Uexp/EPLreg $)$ & 2.24 & 0.73 & 0.68 & 3.93 \\
\hline low_edu (\%) & 35.37 & 14.85 & 6.30 & 66.10 \\
\hline mktcap (\%) & 63.01 & 45.10 & 4.52 & 254.40 \\
\hline attitudes & 0.35 & 0.45 & 0 & 1 \\
\hline open & 64.82 & 35.65 & 13.56 & 176.46 \\
\hline UB_prog & 1.54 & 0.35 & 0.96 & 2.14 \\
\hline
\end{tabular}

The table below provides summary statistics for the variables used in the regression over 54 countries with both EPL and UB systems (period 1985-2000), whose results are displayed in Table 3. This is an unbalanced panel. Observations for OECD countries are available over the entire period, while for ther countries we have for some variables just one observation.

\begin{tabular}{lllll}
\multicolumn{4}{c}{ Table A2.2 Descriptive Statistics for the $\mathbf{5 4}$} & countries \\
Variable & Mean & Std. Dev. & Min & Max \\
UB_gen & 0.15 & 0.19 & 0.05 & 0.73 \\
EPL2 (Botero index) & 0.47 & 0.18 & 0.16 & 0.83 \\
ln(1+UBgen/EPL2) & 2.17 & 1.97 & 0.1 & 5.15 \\
mktcap (\%) & 43.65 & 46.71 & 0.16 & 328.88 \\
tax _prog & 8.66 & 12.79 & 0 & 75 \\
low_edu (\%) & 52.49 & 21.69 & 6.3 & 96.9
\end{tabular}

The table below provides pairwise correlations and Spearman rank correlations between the OECD EPL overall index of employment protection and the index provided by Botero et al.(2004) for the 24 countries in which both indexes are available. As the Botero index was computed with reference to regulations in the 1990s without a specific date, we display yearly correlations over the period covered by our data. $\chi^{2}$ tests of the independence of the two distributions reject the $H_{0}$ hypothesis at 99 per cent 


\begin{tabular}{|c|c|c|}
\hline year & $\begin{array}{l}\text { Pairwise } \\
\text { correlation } \\
\text { coefficient }\end{array}$ & $\begin{array}{l}\text { Spearman } \\
\text { rank } \\
\text { correlation } \\
\text { coefficient }\end{array}$ \\
\hline 1985 & 0,7841 & 0,7650 \\
\hline 1986 & 0,7804 & 0,7627 \\
\hline 1987 & 0,8035 & 0,7967 \\
\hline 1988 & 0,8035 & 0,7967 \\
\hline 1989 & 0,8035 & 0,7967 \\
\hline 1990 & 0,7623 & 0,7367 \\
\hline 1991 & 0,7285 & 0,7331 \\
\hline 1992 & 0,7285 & 0,7331 \\
\hline 1993 & 0,6995 & 0,6954 \\
\hline 1994 & 0,6890 & 0,6636 \\
\hline 1995 & 0,6700 & 0,6603 \\
\hline 1996 & 0,6688 & 0,6499 \\
\hline 1997 & 0,6590 & 0,6644 \\
\hline 1998 & 0,6577 & 0,6734 \\
\hline 1999 & 0,6586 & 0,6646 \\
\hline 2000 & 0,6249 & 0,6379 \\
\hline 2001 & 0,6154 & 0,6360 \\
\hline 2002 & 0,6003 & 0,6211 \\
\hline
\end{tabular}

Figure .1:

Table A2.3. Yearly correlations between the OECD and Botero et al (2004) EPL indexes 


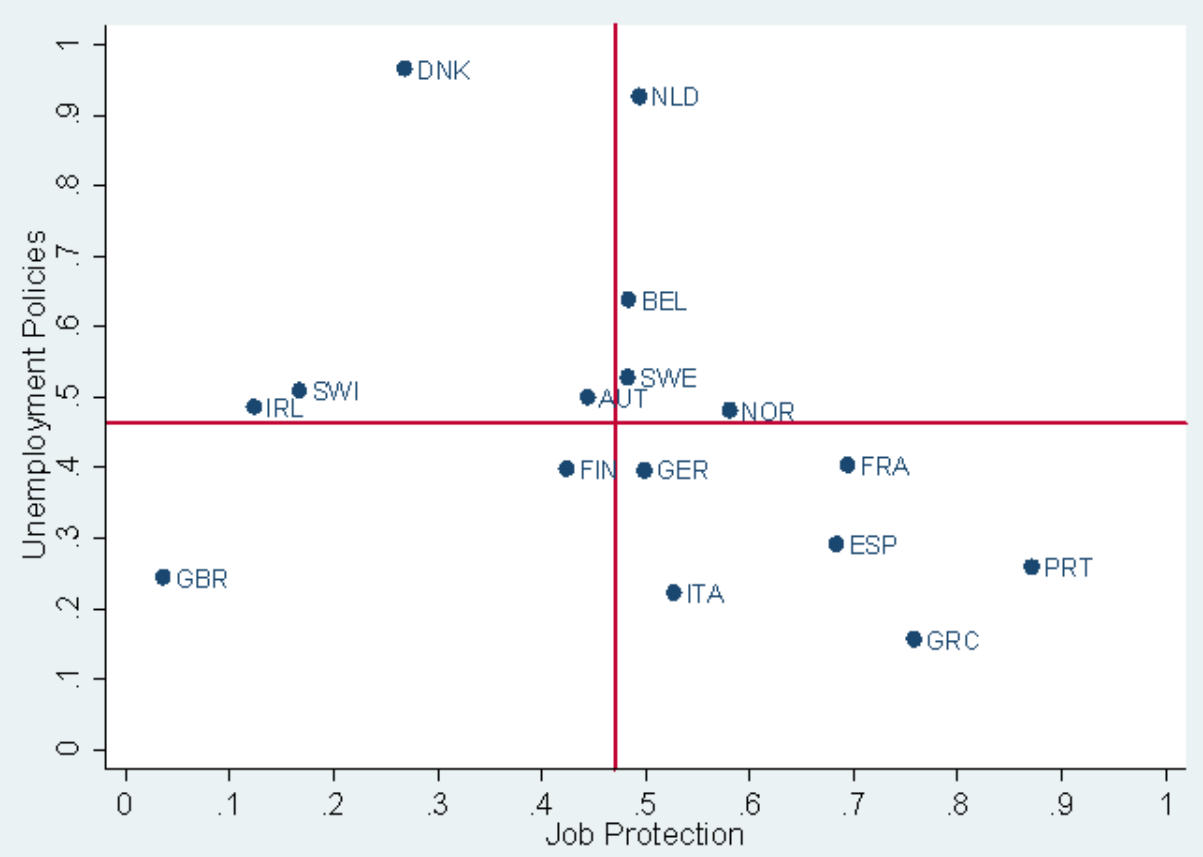

Figure 1: The tradeoff (1996-2005, average period data, European countries)

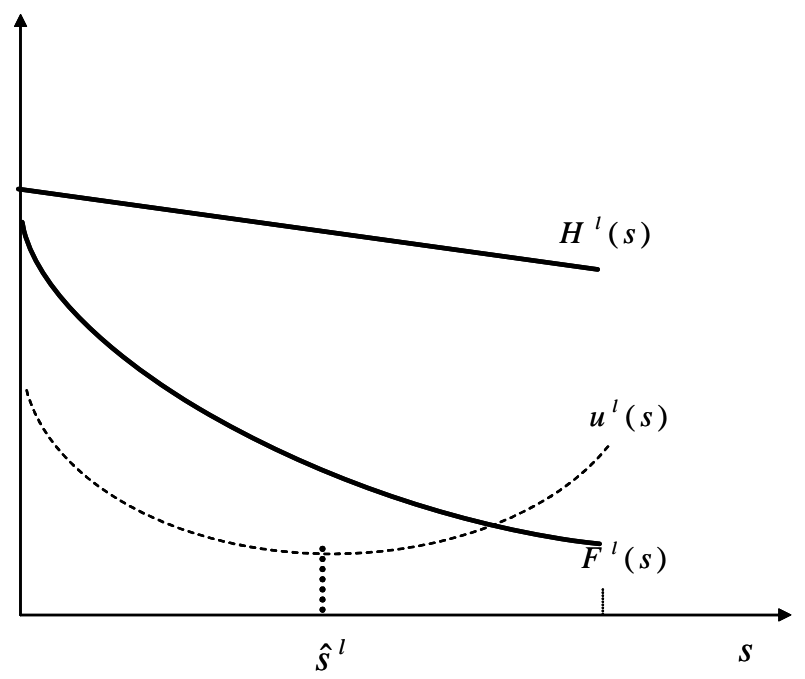

Figure 2: EPL and Low-skill Types 


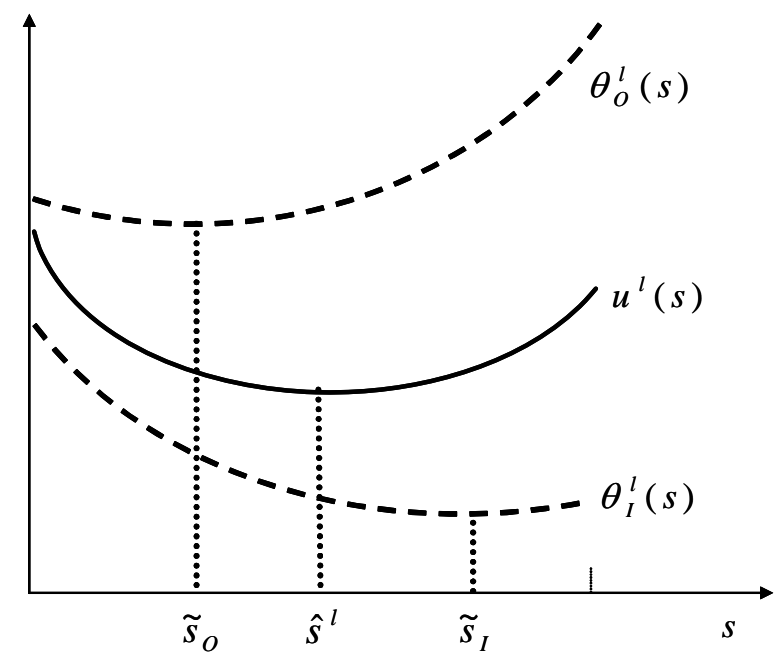

Figure 3: EPL: Low-skill Insiders and Outsiders

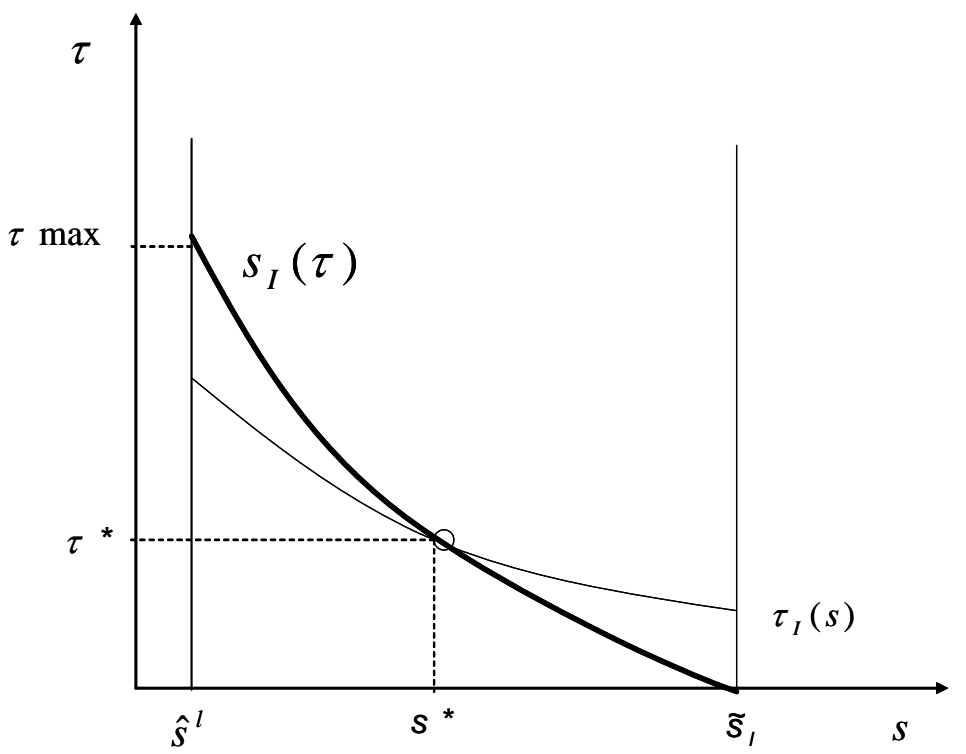

Figure 4: The UB-EPL Political Equilibrium 


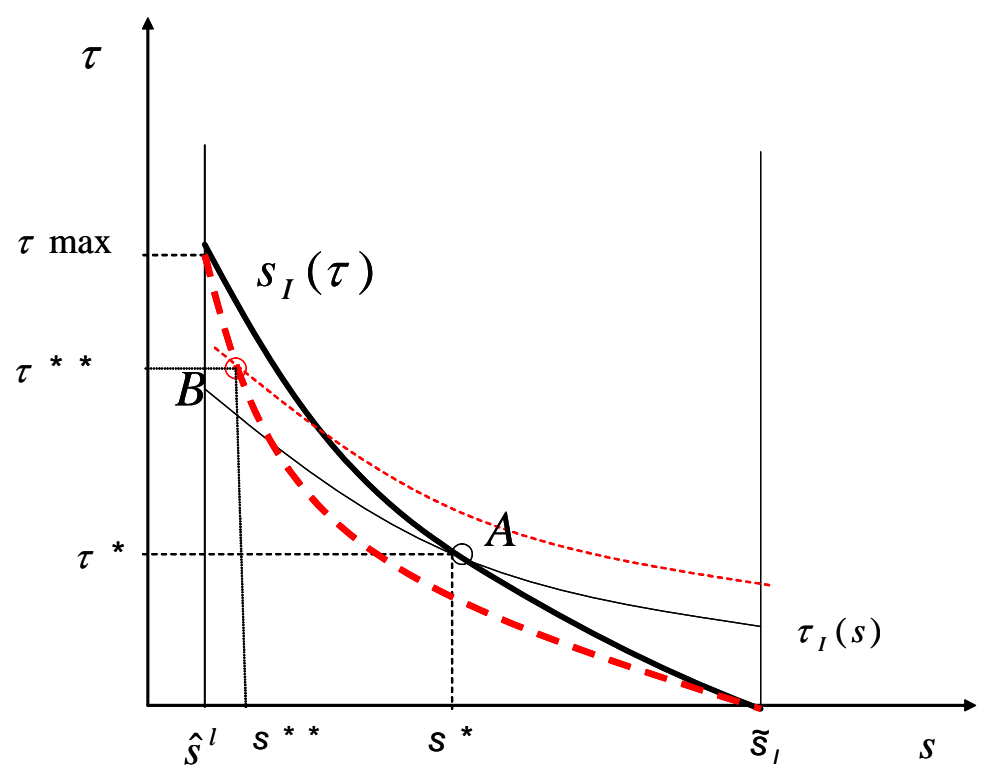

Figure 5: Wage Differential and the EPL-UB Trade-Off

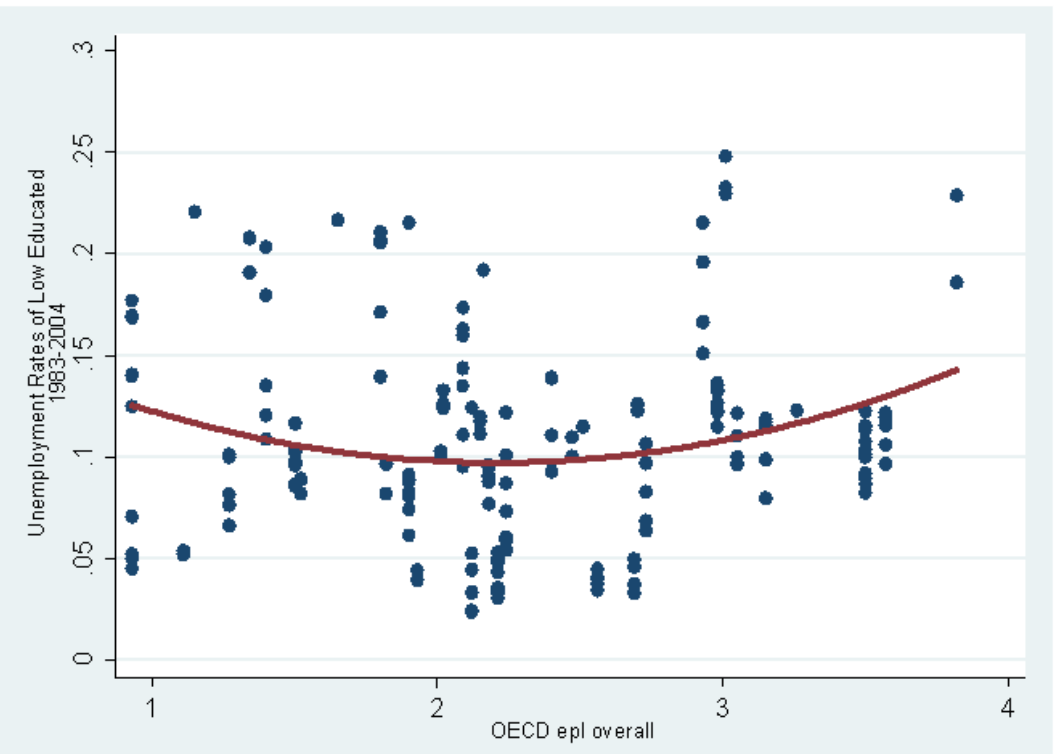

Figure 6: Unemployment rates among the unskilled and EPL (1983-2004, EU countries) 
Table 1: Alternative measures of the trade-off (EU 1996-2005)

\begin{tabular}{rrr}
\hline \hline Epl correlated with & Working-age population & Male prime-age (25 to 45) \\
Uexp & $-.53^{\star}$ & - \\
UBcov & $-.52^{\star}$ & $-.64^{\star \star}$ \\
UBrr & -.22 & - \\
UBrr*UBcov & $-.42^{\star}$ & $-.47^{\star}$ \\
\hline \hline
\end{tabular}

Notes:** significant at $95 ; *$ significant at 90 .

16 observations (all countries displayed in Figure 1,except the UK)

Source: EU-SILC for data on UBcov. OECD for the EPL index and Uexp

Table 2: Estimating the UB/EPL tradeoff (1987-2002, five-years averages)

$\ln (1+$ Uex p/EPLall $) \quad \ln (1+$ Uex p/EPLall $) \quad \ln (1+$ Uex p/EPLreg $) \quad \ln (1+$ Uex p/EPLreg $)$

(1)

(2)

(3)

(4)

\begin{tabular}{|c|c|c|c|c|}
\hline \multirow[t]{2}{*}{ low_edu } & $-0.028^{\star \star \star}$ & $-0.025^{\star \star}$ & $-0.026^{\star \star}$ & -0.020 \\
\hline & $(0.007)$ & $(0.011)$ & $(0.011)$ & $(0.013)$ \\
\hline \multirow[t]{2}{*}{ topmktcap_ubprogr } & $0.398^{\star \star}$ & 0.374 & 0.344 & 0.275 \\
\hline & $(0.190)$ & $(0.218)$ & $(0.213)$ & $(0.249)$ \\
\hline \multirow[t]{2}{*}{ attitudes } & & 0.013 & & 0.283 \\
\hline & & $(0.431)$ & & $(0.494)$ \\
\hline \multirow[t]{2}{*}{ open } & 0.005 & 0.004 & 0.003 & 0.002 \\
\hline & $(0.004)$ & $(0.003)$ & $(0.005)$ & $(0.005)$ \\
\hline \multirow[t]{2}{*}{ Constant } & $2.654^{\star \star \star}$ & $2.661^{\star \star \star}$ & $2.643^{\star \star \star}$ & $2.489^{\star \star \star}$ \\
\hline & $(0.466)$ & $(0.553)$ & $(0.523)$ & $(0.632)$ \\
\hline Observations & 92 & 78 & 92 & 78 \\
\hline$R^{2}$ & 0.475 & 0.424 & 0.360 & 0.317 \\
\hline Number of countr_id & 24 & 22 & 24 & 22 \\
\hline
\end{tabular}

Standard errors in parentheses

*** $p<0.01,{ }^{\star *} p<0.05,{ }^{*} p<0.1$

Notes: See Annex 2 for the list of countries and for summary statistics.

low-edu: share of the population with primary or lower educational attainment.

top markcapUB prog is an interaction variable of a dummy capturing the countries at the top quartile in terms of stock market capitalisation and progressiveness of the UB system (the latter defined as the ratio of the replacement rates at $67 \%$ and $150 \%$ of the APW wage).

Attitudes measures social sanctions against moral hazard

Open is trade turnover over GDP. 
Table 3: Estimating the UB/EPL tradeoff

(between groups panel regression over 54 countries, 1987-2002)

(1) (2) (3) (4)

$\begin{array}{lllll}\text { VARIABLES } & \ln (1+u b / \text { epl } 2) & \ln (1+u b / \text { epl } 2) & \ln (1+u b / \text { epl } 2) & \ln (1+u b / \text { epl } 2)\end{array}$

$\begin{array}{lcccc}\text { low_edu } & -0.028^{* * *} & -0.024^{*} & -0.031^{* *} & -0.026^{*} \\ \text { attitudes } & (0.010) & (0.012) & (0.013) & (0.013) \\ & & 0.489 & 0.137 & 0.253 \\ \text { mkt_cap } & & (0.497) & (0.534) & (0.547) \\ & & -0.011 & \\ & & & (0.008) & \end{array}$

topmktcap_taxprogr

$-0.003$

$(0.022)$

high_income

$2.086^{* * *}$

$1.858 * * *$

$2.183^{* * *}$

$1.997 * * *$

$\begin{array}{cc} & (0.456) \\ \text { open } & -0.008 * * \\ & (0.003)\end{array}$

$(0.500)$

(0.612)

$(0.560)$

Constant

$3.365^{* * *}$

$-0.010^{* *}$

$-0.007$

$-0.010 * *$

(0.004)

(0.004)

(0.004)

(0.710)

$3.368^{* * *}$

$4.021 * * *$

$3.521 * * *$

(0.890)

(0.921)

\begin{tabular}{lcccc} 
Observations & 209 & 126 & 90 & 104 \\
$R^{2}$ & 0.626 & 0.526 & 0.563 & 0.564 \\
Number of countr_id & 54 & 45 & 39 & 39 \\
\hline \multicolumn{5}{r}{ Standard errors in parentheses } \\
& $* * * \mathrm{p}<0.01, * * \mathrm{p}<0.05, * \mathrm{p}<0.1$
\end{tabular}

Notes: See Annex 2 for the list of countries and for summary statistics, Table 2 for the definition of the variables not listed below.

EPL2 is the Botero et al. (2004) index of employment protection.

markcap is stock market capitalisation over GDP

topmarkcap_taxprog is an interaction variable of a dummy capturing the countries at the top quartile in terms of stock market capitalisation and the progressiveness of the tax system, as measured by the ration of the top to the bottom tax rate. 
Table 4. UK and the Rest of the EU15

(1995-2005, average period data)

\begin{tabular}{ccc}
\hline \hline & UK & EU \\
Uexp (Euros) & 6585 & 17112 \\
UBcov & 0.36 & 0.75 \\
UBrr*UBcov & 0.03 & 0.32 \\
UBrr (1 year) & 0.19 & 0.54 \\
EPL overall & 0.62 & 2.62 \\
EPL regular & 0.98 & 2.44 \\
UB_progr & $\mathbf{2 . 0 3}$ & $\mathbf{1 . 1 5}$ \\
mktcap & $\mathbf{1 2 7 . 8 8}$ & $\mathbf{5 4 . 7 7}$ \\
low_edu. & $\mathbf{3 8 . 5}$ & $\mathbf{3 9 . 5 4}$
\end{tabular}

Notes: see Tables 1, 2 and 3 for definitions of the different variables .

Table 5: Lessons from the reformers

(variation in policies in the reform period)

\begin{tabular}{lcccc}
\hline \hline & $\Delta$ EPLreg & $\Delta$ UBgen & $\Delta$ UBprog & $\Delta$ Uexp \\
\hline \hline Spain & $-0,36$ & 0,01 & 0,03 & 0,08 \\
Greece & 0 & $-0,01$ & $-0,03$ & 0 \\
$\Delta$ Spain-Greece & $-\mathbf{0 , 3 6}$ & $\mathbf{0 , 0 2}$ & $\mathbf{0 , 0 6}$ & $\mathbf{0 , 0 8}$ \\
\hline Finland & $-0,14$ & 0 & 0,03 & 0,03 \\
Denmark & 0 & $-0,13$ & $-0,02$ & 0,20 \\
$\Delta$ Finland-Denmark & $\mathbf{- 0 , 1 4}$ & $\mathbf{0 , 1 3}$ & $\mathbf{0 , 0 5}$ & $\mathbf{0 , 1 7}$ \\
\hline \hline
\end{tabular}

Notes: $\triangle E P L r e g:$ change in the value of the OECD EPL index for regular workers over the reform period (1994-2001 for Spain and Greece; 1996-2001 for Finland and Denmark).

$\triangle$ UBgen: change in the generosity of UBs, that is, the coverage of UBs (the fraction of unemployed receiving UBs) multiplied by the average gross replacement rate in the first-year of receipt of benefits. $\triangle$ UBprog: change in the ratio of the replacement rate at two earning levels $(2 / 3$ of the APW wage to 150 per cent of the wage of the APW)

$\triangle \mathrm{Uexp}$ : change in the UB and ALMP expenditure per unemployed person. 